\title{
La Bioética entre la conciencia, la norma y la religión (Acercamiento a un supuesto ético de proyección jurídica de la conciencia personal)
}

\author{
Arturo Calvo Espiga \\ Abogado del Tribunal de la Rota de Roma \\ Catedrático Habilitado de Derecho Eclesiástico del Estado \\ Universidad de Málaga
}

\begin{abstract}
Resumen: Se intenta, en principio, clarificar el concepto de bioética desde los parámetros de las denominadas éticas laicas y éticas religiosas. A continuación, se ofrece, partiendo de la incidencia que los problemas planteados desde la bioética tienen en los ámbitos jurídicos, una posible vía de solución capaz de superar las discrepancias en las soluciones aportadas desde las construcciones teóricas de las bioéticas al uso. Más allá de la ideología que subyace a las distintas opciones en bioética, se prima la asunción de la conciencia personal no sólo como límite negativo (objeciones) de situaciones límite, sino como fuente de derecho, lo que constituye a la persona y a su conciencia en instancia legitimadora de toda decisión que afecte a su vida, salud o integridad.
\end{abstract}

Palabras clave: Bioética, Conciencia, Derecho, Persona, Religión.

Abstract: To start, I try to clarify the concept of bioethics from the parameter of the so-called lay ethics and religious ethics. To continue, I offer, starting from incidence that the problems posed from the bioethics have in juridical fields, a possible way of solution capable of surpass the discrepancies in the solutions showed up from the theoretic constructions of the ordinary bioethics. Further away of the ideology that underlies to the different options in bioethics, we give priority to the assumption of the personal conscience not only as a negative limit (objections) of the extreme situations, but also as a law source, constituting to the person and to his conscience in which legitimizes all the decisions that affect to his life, health or integrity.

Key words: Bioethics, Conscience, Law, Person, Religion.

Sumario: 1. Sobre el significado de Bioética: 1) Los inicios. 2) Dificultades de sistematización. - 2. Para una razón jurídica del concepto de conciencia. - 3. Breve acercamiento a algunos planteamientos confesionales: 1) El pionero magisterio de la Iglesia Católica. 2) Fundamentos 'bio-teológicos' de las religiones monoteístas. 3) El trasunto práctico de los principios teológicos. - 4. Ante la vida y la muerte: ¿obstinación o diálogo?: 1) Las posturas y sus perfiles. 2) ¿Hacia una superación de las diferencias? 3) Horizontes de entendimiento. - 5. El ordenamiento jurídico desde la ética a la sociedad: 1) La conciencia personal, sujeto y fuente de derecho. 2) Viejos esquemas ante nuevos problemas. 3) Persona, norma, conciencia. 
Dadas las características de esta reflexión y el contexto en que se desarrolla, estimamos que el esfuerzo fundamental que estamos llamados a realizar ha de ser metodológico, introductorio, hermenéutico, como se denomina hoy a esa parte introductoria de los distintos saberes científicos en la que se establecen los criterios, pautas y modos que han de seguirse en el estudio y presentación de los problemas sobre los que las distintas ciencias versan y sobre los resultados o intentos de solución a que ellas conducen ${ }^{1}$. Quizás por ello seremos muy parcos en la presentación de soluciones. En el terreno en que nos movemos, sobre todo tal y como se están presentando en la sociedad española ciertas cuestiones relacionadas con la dimensión o patrimonio más importante y exquisito de la persona, cual es la propia vida, las soluciones rápidas y fáciles son patente segura de error o de manipulación.

También hemos de evitar la supeditación o utilización de importantes y profundos interrogantes del hombre actual, que afectan radicalmente a lo más profundo de la persona y de su propia continuidad y supervivencia como ser único y libre, a o para fines que, al margen de las auténticas necesidades y proyectos de mejora y progreso del ser humano, sólo buscan el triunfo de una determinada ideología, la cínica perpetuación en el poder e incluso la inadecuada satisfacción de inconfesados intereses económicos y comerciales.

\section{Sobre el significado de Bioética}

Bioética es una de las palabras más utilizadas y socorridas en los últimos años ${ }^{2}$. Desde la reflexión científica, filosófica, jurídica y social en torno a la genética hasta la problemática que en su momento plantearon, por ejemplo, los trasplantes de órganos o las polémicas que hoy existen en torno a la muerte buscada, querida y procurada, el recurso o referencia a la bioética es moneda de cambio habitual para filósofos, moralistas, periodistas, articulistas, divulgadores, conferenciantes, tertulianos, editorialistas, etc. Pero ¿qué significa bioética?, ¿por qué esta palabra y no otra?, ¿por qué no thanatoéti$c a$, puesto que la gran mayoría de las veces que se recurre a este vocablo es para abrir vías a la muerte comprendida en otro eufemismo que no viene al caso $^{3}$ ?

\footnotetext{
${ }^{1}$ El presente artículo reproduce, casi en su totalidad, la exposición de una sesión de trabajo realizada en el mes de enero de 2006 dentro de los Cursos que la Universidad de Málaga organiza todos los años para la formación y promoción de personas mayores.

${ }^{2}$ Sobre el origen, historia y evolución de este término, puede verse W. T. REICH, «The Word 'Bioethics': Its Origins and the Legacies of Those Who Shaped It», Kennedy Institute of Ethics Journal, 1994, 319-333; IDEM, «Il termine 'Bioética'. Nascita, provenienza, forza», Itinerarium 2-3, 1994, 33-71.

${ }^{3}$ Cf. G. Fornero, Bioetica cattolica e bioetica laica (Milán 2005), 1-21.
} 


\section{1) Los inicios}

Sólo hay que remontarse al año 1970 para descubrir el inicio y consagración de este vocablo en el sentido significativo supuesto que arbitrariamente ha sido aceptado como tópica moneda de cambio que, con mucha frecuencia, encubre, en su uso, más que lo que explica o aclara. En este año, el cancerólogo estadounidense VAN RENSSELER POTTER publicó dos artículos que fueron completados con una posterior monografía en el año 1971, en que explica que con este término intentaba unir o relacionar las ciencias de la vida, las denominadas life sciences, con una comprensión axiológica (ética) de la vida que, al menos, facilitase los fundamentos o los medios para elaborar una especie de ciencia de la supervivencia (science of survival) ${ }^{4}$. El propio POTTER explicaba en un trabajo posterior que había elegido el prefijo a la raíz bio- para significar el saber biológico o, lo que es lo mismo, la ciencia de los seres vivientes; y que había optado por -ética para indicar el saber o la ciencia acerca de los sistemas de valores humanos ${ }^{5}$.

POTTER intentó, sobre todo, facilitar o diseñar un puente o sistema de relaciones capaz de garantizar la supervivencia y conservar el bienestar del hombre como consecuencia de la situación, auténtico cáncer para la naturaleza, creada por el incontrolado desarrollismo generado como consecuencia de la revolución científica y técnica. Sin embargo, en los años que siguieron a la formulación de Potter, prevaleció el significado que dieron al término tanto ANDRÉ HELLEGERS ${ }^{6}$, físiólogo de origen holandés especializado en embriología humana, fundador en el año 1971 en la Universidad jesuítica de Georgetown (Washington) del Kennedy Institute of Ethics, como un relevante miembro de éste, WARREN T. REICH, que, en la introducción a la Encyclopedia of Bioethics, propone la definición de bioética que hoy ya se considera clásica: «el estudio sistemático de la conducta humana en el ámbito de las ciencias de la vida y del cuidado de la salud, en cuanto examinada y juzga-

${ }^{4}$ Cf. V. R. PotTER, «Bioethics. The Science of Survival», Perspectives in Biology and Medicine 14, 1970, 127-153; IDEM, «Biocybernetics and survival», Zygon, Journal of Religion and Sciences 5, 1970, 229-246; IDEM, Bioethics. A Bridge to the Future (1971). Aun cuando Potter explica que el término le vino de repente, como por una inspiración, al final de los años sesenta, no lo hizo público hasta los trabajos citados. Posteriormente, el propio Potter escribió una nueva obra conceptualmente muy crítica con el desarrollo de la bioética: Global Bioethics. Building on the Leopold Legacy (1988).

${ }^{5}$ Cf. V. R. POTTER, «Humility and Responsibility - A Bioethic for Oncologist: Presidential Address», Cancer Research 35, 1975, 2297-2306, de forma especial las páginas 2298-2300.

${ }^{6}$ Cabe señalar que Hellegers no sólo ha sido la primera persona en dirigir un Instituto dedicado específicamente a la Bioética, sino que la propia palabra aparecía en su título originario establecido por el propio Hellegers y que, precisamente por ello, se denominó Joseph and Rose Kennedy Institute for the Study of Human Reproduction and Bioethics. El propio Reich considera a Potter y Hellegers como padrinos simultáneos del término bioética: cf. W. T. ReICH, «The Word 'Bioethics'. The Struggle Over its Earliest Meanings», Kennedy Institute of Ethics Journal 5/1, 1995, 19-34. 
da a la luz de valores y principios morales» ${ }^{7}$. Es de notar que el mismo PoTTER, ante la evidencia del poco éxito de su pionera aportación a la conceptualización del término bioética y el indiscutible predominio de la de HELLEGERS-REICH, acabará reconociendo que «la especial atención a los problemas suscitados en el ámbito de la ética médica hizo olvidar la idea originaria de bioética tal como yo la había concebido en referencia al marco global de las ciencias de la vida» ${ }^{8}$.

Es muy importante, a la hora de situar e intentar comprender las divergencias en torno al propio concepto y contenido de este término, no olvidar la ambigüedad significativa que arrastra desde sus orígenes. Mientras POTTER, en su perspectiva pionera, pretendía que la bioética se situase dentro de parámetros científicos de matriz biológica, encuadrándola, por tanto, en el marco de la biological science, para los estudiosos del entorno del Kennedy Institute la bioética habría de situarse más en el campo de la ética aplicada (applied ethics) orientada primariamente al estudio de las cuestiones y problemas derivados de la investigación biomédica, de la curación de las enfermedades y de la mejora de la calidad de vida y de la salud. Según esta perspectiva, la bioética ha de situarse en el plano más general y básico de lo que podríamos considerar como una antropología ética, entendida fundamental y básicamente como la infraestructura humana que da sentido a términos como salud y bioética. En definitiva, se trataría de defender y a la vez profundizar en la dignidad del ser humano, y en todo aquello que lo humaniza, de cara a los grandes avances biomédicos, en su más amplio sentido significativo, del mundo actual: desde la genética hasta todo lo referido a la patología de la muerte o del dolor'.

La recepción del término bioética, importado de los Estados Unidos, se realizó con más facilidad en aquellos países europeos, como, por ejemplo, Inglaterra, donde se estaba más familiarizado con la filosofía analítica. En Alemania y Francia, el proceso de recepción del término ha sido más dificultoso y problemático y se circunscribió su uso significativo mediante el recurso a fórmulas del tipo éthique bio-medical, medizinische Ethik, Ethik des Lebens, etc. En Italia, si bien tanto su implantación como su inmediato desarrollo encontraron dificultades tanto en el mundo médico como en el académico, ha acabado siendo muy bien acogido tanto en los ambientes laicos como católicos ${ }^{10}$. A semejanza de las circunstancias académicas que ro-

${ }^{7}$ W. T. REICH (ed.), Encyclopedia of Bioethics, vol. 1 (Nueva York 1978) XIX.

${ }^{8}$ V. R. PotTer, La prima idea di bioetica, en G. Russo (ed.), Bioetica generale e fondamentale (Turín 1995) 5-18, por lo que se refiere a la cita, página 11.

${ }^{9}$ Cf. J. Masiá Clavel, Bioética y antropología (Madrid 1998), 11-32.

${ }^{10}$ En Italia fue Menico Torchio, profesor de Biología marina en la Universidad de Pavía, quien introdujo el término bioética en el argot científico italiano a través de un artículo publicado en junio de 1973 en la revista Natura y que tituló «Rapporti uomo-Natura secondo le principali matefisiche orientali, loro implicazioni bioetiche ed ecologiche», según ha 
dearon sus orígenes, también en España han sido pioneros en la introducción y cultivo de esta disciplina los jesuitas a través de sus instituciones universitarias: nos referimos en concreto a la Cátedra de Teología Moral de la Facultad de Teología de la Universidad Pontificia de Comillas y al que hasta su muerte fue su titular, el P. Javier Gafo Fernández que, a su vez, era Director de la Cátedra y Máster de Bioética de la mencionada Universidad ${ }^{11}$.

\section{2) Dificultades de sistematización}

Sin embargo, aunque nos hallemos ante un neologismo generalmente admitido y continuamente utilizado por médicos, juristas, filósofos, periodistas y por la gran mayoría de las personas que probablemente jamás se encontrarán en toda su vida ante dilema alguno relacionado con la bioética, esta situación no resulta en modo alguno equivalente a la unanimidad en su definición y comprensión; antes al contrario, en lugar de eliminarse o allanarse, las divergencias acerca de su naturaleza, de sus ámbitos de aplicación, de su finalidad e incluso de su propio origen parece que aumenten a medida que crece el número de estudiosos que desde distintas perspectivas científicas se acercan a su tratamiento. Al término de su exposición sobre las dificultades con que tropiezan quienes intentan encontrar una «definición» adecuada de bioética, el profesor Russo sentencia, con toda razón: «Parafraseando una expresión de San Agustín, se podría decir que si nadie me pregunta qué es

puesto de relieve el profesor Russo. Puede verse, al respecto, G. Russo, Storia de la bioetica dalle origini ad oggi, en IDEM, Storia della bioetica. Le origini, il significato, le istituzio$n i$ (Roma 1995), 44-81. De la importancia que actualmente se da en Italia a los problemas que se plantean desde la bioética, así como a su naturaleza y contenido tanto material como formal, da sobrada cuenta la abundancia de títulos publicados en aquella nación sobre estas cuestiones y la gran acogida que tienen entre los lectores a juzgar por el espacio que estos temas ocupan en las estanterías de las librerías italianas.

${ }^{11}$ Cátedra que extiende su influencia más allá de las fronteras hispanas. También en otra Universidad jesuítica, la de Sophia, entre las más prestigiosas de Japón, se dejan sentir los ecos de esta institución española a través, por ejemplo, del jesuita y profesor en ambas Universidades, P. Juan Masiá Clavel que tanto en Madrid como en Tokio es profesor de Antropología Filosófica y Bioética. Son ya muy numerosas las tesis doctorales realizadas en ambas instituciones sobre cuestiones directamente relacionadas con la bioética. Por lo que se refiere al caso español, también cabe mencionar la línea de investigación que se sigue, y que ya ha dado sus primeros frutos literarios (Cf. I. MARTín SÁNCHEZ [ed.], Bioética, Religión y Salud, Madrid 2005; y Bioética, Religión y Derecho [Actas del curso de verano de la Universidad Autónoma de Madrid celebrado en Miraflores de la Sierra del 14 al 16 de julio de 2005], Madrid 2005), por el equipo, dirigido por su catedrático titular, de la Cátedra de Derecho Eclesiástico del Estado de la Universidad Autónoma de Madrid. A partir del parámetro tan objetivo de la presencia de títulos en los estantes de las librerías, que hemos seguido en el caso de Italia, cabe concluir que el interés por estos problemas en España está a años luz de retraso respecto a otras naciones. Quizás sea consecuencia de esa tendencia tan española de creernos especialistas en todo sin saber de nada. 
la bioética, lo sé; pero en el momento que me preguntan cualquier cosa sobre ella, no lo sé» 12 .

La complejidad y dificultad que rodean a la mera fijación de su significado aumentan, si cabe, cuando nos acercamos al modo como las distintas tendencias explican o delimitan el propio contenido material de este término. Para unos, la bioética no va más allá de ser una rama o subespecie de la ética que versa, directamente, sobre el nacimiento, la salud y la muerte del ser humano; o bien, que se ocupa del fundamento y cobertura moral de los problemas jurídicos surgidos en torno a cuestiones como el aborto, la eutanasia, el encarnizamiento terapéutico, los trasplantes de órganos, la fecundación asistida, el tratamiento de embriones, la manipulación genética, etc. ${ }^{13}$

Un segundo grupo, por el contrario, estima que esta concepción restringe demasiado el verdadero contenido de la bioética y, siguiendo a Potter, optan por una comprensión de la bioética en la que se integran la médica (medical bioethics) junto con la ecológica (ecological bioethics) e incluso con la que ha venido a denominarse ética global (global bioethics) que, en si misma, trasciende al propio ser humano: «Una bioética global, como ciencia de la supervivencia, debe poder definir lo que es justo y lo que es erróneo en términos de conservación y protección de la biosfera» ${ }^{14}$.

El propio Reich, en la segunda edición revisada y ampliada de su Encyclopedia, ofrece una nueva definición más extensiva de bioética, considerándola ahora como «el estudio sistemático de las dimensiones morales -incluso la mentalidad moral, las decisiones, la conducta, las líneas de orientación, etc.- de las ciencias de la vida y de la salud, a través de una variedad de metodologías éticas en un marco interdisciplinar» ${ }^{15}$.

La controversia en torno al contenido de la disciplina afecta también de forma relevante a la fijación del propio origen del término como, desde otra perspectiva, ya hemos apuntado anteriormente. Sin discutir el hecho de que sólo desde los años setenta se ha comenzado a reflexionar, directa y reflejamente, sobre estos problemas a partir de un neologismo; sin embargo, no falta quien se resiste a hacer coincidir el advenimiento de la bioética con el nacimiento de la palabra «bioética». Prefieren situar su inicio en la encrucijada histórica del pasmo producido entre el proceso de Nuremberg y la imagen pública de la irracionalidad de los crímenes nazis que, en el plano jurídico, derivó en

${ }^{12}$ Cf. G. Russo, Bioetica, en IDEM, Enciclopedia di bioetica e sessuologia (Turín 2004) 327-332, de manera especial la página 327.

${ }^{13}$ Cf. H. Kunse y P. Singer, A Companion to Bioethics (Oxford 1998); E. LeCaldano, Bioetica. Le scelte morali (Roma-Bari 1999).

${ }^{14}$ V. R. PotTer, L'idea originaria di bioetica, en G. Russo (ed.), Storia de la bioetica..., cit., p. 327. De interés también las páginas 328-332.

${ }_{15}$ W. T. ReICH, Encyclopedia of Bioethics (Nueva York 1995) XXI. Puede verse también S. SPINSANTI, «Incontro con Warren Reich», L'Arco di Giano, n. 7, 1995, 219. En esta misma dirección se orienta Juan Masiá Clavel en la obra citada en la nota... 
la Declaración de Derechos del Hombre de 1948 y, en el ámbito filosófico, produjo la vuelta al iusnaturalismo de la década de los cincuenta ${ }^{16}$.

Otros, por el contrario, estiman que la bioética, tal y como hoy se plantea su estudio y contenidos, surge como consecuencia de la ruptura cultural que tiene lugar entre la década de los sesenta y los setenta y de su incidencia en el cambio de criterios y principios éticos y morales, así como de modelos y paradigmas políticos, operado a continuación en las sociedades occidentales ${ }^{17}$. Así pues, para los primeros, la bioética guarda una relación de continuidad con el pasado, con la ética tradicional, y en realidad no va más allá de ser un tipo de aplicación de los principios morales ya conocidos a unas circunstancias nuevas y cambiantes ${ }^{18}$. Los segundos, por el contrario, piensan que la bioética supone una auténtica ruptura con el pasado y, en consecuencia, la consideran una nueva ética de corte revolucionario y opuesto, en gran medida, a la tradición moral de Occidente ${ }^{19}$.

La comprensión efectiva del término bioética y de los contenidos materiales que en él encuentran cobertura también guarda, de hecho, una estrecha dependencia de la idea de ética que fundamente o dé cobertura a la propia reflexión bioética. Y ello al margen de que la bioética se considere, según hemos apuntado, como una subespecie del genérico ética o bien como una

16 «Cuando a partir de los años cincuenta de este siglo se hace patente en los ambientes jurídicos lo que comúnmente se ha denominado crisis del derecho, en realidad, a través de la misma, se está sometiendo a crítica no propiamente el derecho sino los ideales del individualismo jurídico; o lo que es lo mismo, según todos los indicios, esta crítica generalizada al derecho no es, en el fondo, otra cosa que una dura, aunque no siempre expresamente manifiesta, reacción contra el positivismo jurídico. Esta reacción contra el positivismo ha situado en este momento la cuestión del derecho en una dimensión propia que, a la vez que renuncia a cualquier atadura o dependencia respecto al idealismo jurídico neokantiano, también se aleja del formalismo lógico, donde la ley, en cuanto tal, adquiere una fuerza y un predominio absoluto en el tráfico de las relaciones jurídicas... por otra parte, intenta abrirse camino en la intrincada maraña del mundo del derecho un realismo jurídico nítida y claramente antipositivista que, en el fondo y llámesele como se quiera, es simplemente un redescubrimiento del derecho natural. Redescubrimiento que en ningún momento ha de suponer retorno o reviviscencia de anacrónicos e ilustrados tópicos del viejo iusnaturalismo racionalista» (A. CAlvo Espiga, «Acercamiento a la incidencia del derecho natural y de los derechos humanos en la elaboración del derecho», Scriptorium Victoriense 32, 1985, 286-287). También puede verse E. SGRECCIA, Manuale di bioetica, vol. I. Fondamenti ed etica biomedica (Milán 1999), 23-47.

${ }^{17}$ Cf. S. MAFFETONE, Il valore della vita. Un'interpretazione filosofica pluralista (Milán 1998), 170-173; M. MorI, «La bioetica: che cos' è, quand' è nata e perché», Bioetica, n. 1, 1993, 115-143; de manera especial 133-135.

${ }^{18}$ Cf. F. Bellino, Bioetica e qualità della vita. Fondamenti (Nardò 1999), 21-39; K. Danner Clouser, Bioethics, en W. T. ReICH (ed.), Encyclopedia of Bioethics..., cit., vol. I, pp. 112-129.

${ }^{19}$ Cf. M. Mori, Conclusioni, en E. D’ Orazio y M. Mori (ed.), «Quale base comune per la riflessione bioetica in Italia? Dibattito sul Manifesto di bioetica laica», Notizie di Politeia 12/41-42, 1996, 80-87; U. SCARPELLI, Bioteca laica (Milán 1998) 185-191. 
disciplina autónoma ${ }^{20}$. Aun así, al menos metodológicamente, las diversas y variadas corrientes que conforman el espectro de la bioética pueden reconducirse a dos grandes modelos teóricos o paradigmas que, como es lógico, se inspiran en y responden a dos concepciones generales del mundo y a dos sistemas filosóficos distintos: el primero procedería de una matriz de carácter y fundamento religiosos y el segundo respondería a un pensamiento de extracción y raíces laicas.

De forma eminente, aunque no exclusiva, el primer modelo se concretaría especialmente en los principios de la bioética católica en torno a la sacralidad de la vida o a la santidad de la vida, según se ha acuñado en ámbito anglosajón ${ }^{21}$. El segundo modelo está representado, sobre todo, por la bioética laica de la cualidad o calidad de la vida. ${ }^{22}$ Ciertamente, aunque no sean los únicos en sentido absoluto, estos dos modelos son sin ninguna duda los que, de hecho, han monopolizado, al menos en Occidente, la determinación del propio concepto de bioética, de sus límites y contenidos; y siguen siendo los marcos en que se sitúan actualmente los debates y discusiones sobre las cuestiones candentes en su ámbito ${ }^{23}$.

${ }^{20}$ Así se habla, entre los autores, de bioéticas de tendencia ontologista o bien de corte utilitarista, kantianas, subjetivistas, liberales radicales o hedonistas, sociobiologistas o personalistas, etc. Puede verse, al respecto, R. MoRDACCI, Una introduzione alle teorie morali. Confronto con la bioetica (Milán 2003); M. MORI, Bioetica. 10 temi per capire e discutere (Milán 2002): sobre esta cuestión concreta, las páginas 141-144.

${ }^{21}$ Algunos autores prefieren denominar a «su bioética» como bioética personalista en lugar de denominarla sin más como católica y se lamentan de que, con frecuencia, quienes no comparten o se oponen a los principios de los que ellos parten y defienden, al calificar de católicas sus posiciones, en realidad lo que buscan es «desacreditar al adversario»: «La bioetica personalista è stata abilmente etichettata come 'cattolica', per così ghettizzarla all'interno della Chiesa. Viene, infatti, facilitata la credibilità dell'affermazione che essa si fonda su concezioni e principi razionalmente indimostrabili, che solo chi crede in Dio e nella rivelazione cristiana può accettare. Si addebita pure ad essa di risovere i problemi con l'argomento di autorità, cioè in obbedienza all'autorità del Magistero ecclesiale» (L. CicCONE, Bioetica. Storia, principi, questioni, Milán 2003, 25). Quienes se han sentido aludidos por esta postura responden insistiendo en la equivocidad, amplitud y diversidad de la denominación personalista, al tiempo que recuerdan que «todo investigador es libre de elegir los términos que estima o retiene más apropiados al conjunto de su razonamiento y, además, no resulta incorrecto o desacreditador hablar de 'bioética católica'» (G. ForNERo, Bioetica cattolica..., cit., p. 23). Sin embargo, estos mismos autores no suelen reaccionar con la misma acribia metodológica, cuando desde posturas distintas a las suyas y ante las respuestas que se dan a determinados problemas, se les considera seguidores de una ética de muerte, más que de una moral de vida.

${ }^{22}$ Cf. E. LeCALDANO, «Una morale libera da comandamenti dopo l'etica della sacralità della vita», Bioetica 1997/1, 81-88.

${ }^{23}$ «Legisladores, médicos y cualquier ciudadano deben reconocer que el verdadero problema radica en la alternativa de afirmar y tutelar la sacralidad de toda vida humana o de abrazarse, por el contrario, a una ética social para la que ciertos tipos o formas de vida humana son apreciables, mientras otros no lo son. Como nación, debemos elegir entre ética de la sacralidad de la vida y ética de la 'cualidad' de la vida» (R. REAGAN, "Abortion and the Conscience of the Nation», Human Life Review 9/2, 1983, 13-14). 
No faltan quienes, en desacuerdo con estos planteamientos polémicos y hasta hostiles sobre la naturaleza de la bioética, han propuesto, sin mucho éxito, una vía media a favor de una bioética sin adjetivos, insistiendo en que «la bioética no es ni religiosa, ni laica; es simplemente bioética» ${ }^{24}$.

\section{Para una razón jurídica del concepto de conciencia}

Tal como ha llegado a nuestro lenguaje, el término conciencia deriva su etimología del latín conscientia y del griego syneídesis, sustantivo equivalente a conciencia, o synoida, forma verbal que significa ser consciente o saber $^{25}$. El sustantivo syneídesis se encuentra por primera vez en DEMÓCRITO (Fragm. 297) y designa, según las circunstancias y el contexto en que aparece, tanto el conocimiento como la conciencia, e incluso la desazón de quien se ve acosado por los escrúpulos. En sus inicios, syneídesis, tuvo una significación más noética que moral y designaba, sobre todo, la capacidad personal de relacionarse consigo mismo, especialmente en lo que respecta a la consideración o percepción retrospectiva del propio pasado, circunstancia que acabó revistiendo al término conciencia del significado moral que ha predominado, ya a partir del siglo I a. C., en el lenguaje común ${ }^{26}$.

Diversidad significativa que también es una constante en las obras de la Patrística y de los escritores eclesiásticos de los orígenes, así como en las pri-

${ }^{24}$ R. LuCAS LuCAS, Bioetica per tutti (Cinisello Balsamo 2002) 6. La contestación a esta postura más aséptica o conciliadora, según se mire, ha venido, sobre todo, de los ambientes laicos: «Un cattolico e un laico rimangono un cattolico e un laico anche quando si dedicano a questioni come l'aborto o la determinazione del momento di morte prima di un trapianto. Certe diversità, anzi certi contrasti, limitati e attuiti nella vita quotidiana, nel diritto e nell'economia, da secoli di convivenza, sui nuovi problemi bioetici posti dallo sviluppo scientifico e tecnologico riacquistano feschezza e asprezza» (U. SCARPELLI, Bioetica laica..., cit., p. 19)

${ }^{25}$ Para todo este epígrafe puede verse A. CALvo EsPigA, «Conciencia y Estado de derecho», Laicidad y libertades. Escritos jurídicos 1, 2001, 17-45; de forma especial, las páginas $18-25$.

${ }^{26}$ «Esta evolución comienza con los 'siete sabios'... y el término menudea con este significado a partir del s. I a. C., sobre todo en los historiadores (Dión, Estrabón, Plutarco). Según que el hombre pueda o no justificar su obra ante esta instancia crítica que lleva en sí mismo, se habla de buena o recta (agathé u orthé) y mala (deiné y poneirá) conciencia. Además la buena conciencia es considerada, por regla general, como la que lleva a la paz, como la conciencia tranquila, mientras que la mala conciencia se hace notablemente desagradable, por el hecho de que intranquiliza al que la posee (cf. Eurípides, Or. 396, donde el matricida Orestes aduce como enfermedad que le aniquila la conciencia en cuanto conocimiento de las malas acciones). En la literatura griega las Erinnias son la personificación mitológica de esa mala conciencia que acosa al hombre» (H.-Chr. Hahn, Conciencia, en L. Coenen, E. Beyreuther y H. Bietenhard, Diccionario Teológico del Nuevo Testamento, vol. 1, Salamanca, 1980, 286). 
meras versiones o traducciones de los textos vétero y neotestamentarios donde syneídesis y conscientia son traducidas por términos o conceptos tan dispares como conocimiento en general, referido sobre todo a la ciencia profana, intuición, saber, sentido, opinión, forma de pensar, conciencia, testigo, norma de valores, orientación moral, consciencia de valores morales, deber interior, conocimiento del bien y del mal, etc.; sin olvidar que también, con frecuencia, el término conciencia viene utilizado en el sentido funcional de buena o mala conciencia o, lo que es lo mismo, en su dimensión moral ${ }^{27}$.

A la dificultad que ya de por sí supone la fijación del contenido de un concepto histórica y lingüísticamente tan complejo, se suma el hecho de que la reflexión occidental se halla condicionada y hasta determinada por el lastre ideológico que desde el tardío medievo arrastra este concepto a causa del retroceso de la concepción neotestamentaria de syneídesis en favor de una interpretación predominantemente moral y alegórica ${ }^{28}$, así como de la práctica identificación de la conciencia con su dimensión ascético-mística, en la que lo teológico-especulativo o filosófico-psicológico pasa a un irrelevante segundo plano en favor de su instrumentalización fáctica para la formación y progreso de la vida religiosa y espiritual, o dicho de otro modo, utilizándola como medio para aislar y evitar el pecado ${ }^{29}$.

Al margen, pues, de las distintas definiciones que se han elaborado del término conciencia, siempre dependiendo del ámbito metodológico desde el que se intente abordar su estudio, nosotros procuraremos operar, en principio, más con una descripción que con una definición, centrando nuestro interés sobre todo en los aspectos óntico-personales sin abandonar los que podríamos denominar como psico-morales ${ }^{30}$. En esta exposición, intentare-

\footnotetext{
${ }^{27}$ Para una información más completa no sólo de los aspectos filológicos sino también de los ideológicos, filosóficos y religiosos, así como de la problemática implicada en la utilización de estas expresiones por los autores referidos y por quienes posteriormente los han estudiado y traducido, puede verse J. STENZENBERGER, Über 'syneídesis' bei Klemens von Alexandrien, en VARIOS, Festgabe für Seppelt (Munich 1953) 27-53; IDEM, Conscientia bei Tertullianus, en VARIOS, Vitae et veritati. Festgabe für Karl Adam (Dusseldorf 1956) 28-43.

${ }^{28}$ Cf. C. SPICQ, Esquisse d'une histoire de l'exégèse latine au moyen âge (París 1944) 257-288.

${ }^{29}$ Hugo de San Víctor y Bernardo de Claraval dieron un gran impulso a esta línea de pensamiento, ejerciendo además una gran influencia entre los continuadores de ésta, que podríamos considerar, sacralización de la conciencia personal, tales como Pedro Celense, Ricardo de San Víctor, Tomás de Kempis y otros.

${ }^{30}$ El Diccionario de la Lengua Española editado por la Real Academia Española entiende, con un claro predominio, a nuestro entender, de su dimensión perceptivo-psico-estimativa, por conciencia la «propiedad del espíritu humano de reconocerse en sus atributos esenciales y en todas las modificaciones que en sí mismo experimenta». MARÍA MOLINER, en su Diccionario del uso del español, describe la conciencia, siempre con un predominio de lo dinámico-cognoscitivo, como el "conocimiento que el espíritu humano tiene de sí mismo» $\mathrm{y}$ también como la «facultad que hace posible ese conocimiento». También puede verse, al respecto, D. LlamaZares Fernández, Derecho de la libertad de conciencia, vol. I. Libertad
} 
mos, pues, centrarnos en el análisis o descripción de la raíz o principio fundamental que determina o cualifica a la conciencia como realidad personal que trasciende no sólo los estados o situaciones subjetivas que invaden o por los que puede atravesar la persona sino, incluso, el medio o ambiente orgánico, físico e incluso social en que se origina.

A partir de los resultados ofrecidos por los abundantes intentos realizados desde la psicología y la metafísica, en orden a determinar o precisar el contenido estricto o los contenidos esenciales de la conciencia, puede plantearse el acercamiento a un cierto perfil definitorio de ésta. Si desde la psicología se pone énfasis en el drama interior de la persona atenazada por la inadecuada proporcionalidad entre los fines y objetivos ínsitos en su propio ser y los medios y posibilidades de que dispone para alcanzarlos, las teorías metafísicas sobre ella se han esforzado, al menos desde los supuestos de la filosofía de Descartes, por intentar liberar a la conciencia, elevándola al aséptico Olimpo de la razón, de todos los vínculos vitales que la unen e incluso identifican con cada sujeto personal y único. La trascendencia que, desde distintos supuestos y planteamientos, todas las teorías metafísicas reconocen a la conciencia con relación al medio físico y orgánico, en su más amplia y omnicomprensiva acepción en que ésta se inserta, muestra sin ningún género de duda que la conciencia, en su más profunda esencia, participa en o pertenece a un mundo que se sitúa más allá de la mera experiencia sensible... a un mundo individual y único entretejido de racionalidad en sus verdades y de personalismo en sus acciones.

Ahora bien, nunca la metafísica debe alejar al jurista de la prudencia. Identificar la conciencia con la razón o el espíritu, se escriba con mayúsculas o minúsculas, aboca inmediatamente a la desnaturalización de la conciencia y a su consiguiente desaparición. Radicada en la trascendentalidad y trascendencia de la racionalidad, la conciencia participa plenamente, me atrevería a decir que como dimensión fundamental de ésta, del mundo espacio-temporal concreto, en el que todo fluye sobrevolando la relatividad de lo

de conciencia y laicidad, Madrid 1997, 11; IDEM, Derecho Eclesiástico del Estado. Derecho de la libertad de conciencia, Madrid 1991², p. 500. Hemos de llamar la atención sobre la constancia con que, al tratar de la conciencia, se invocan la dimensión espiritual, en su más amplia acepción, así como los valores, no los juicios concretos, morales de la persona, lo que lógicamente ha de abocarnos, desde la perspectiva jurídica que asumimos, a una estimación del topos conciencia más objetiva y totalizante de la persona, como ya apuntó el propio Tribunal Constitucional: «Junto al valor de la vida humana y sustancialmente relacionado con la dimensión moral de ésta, nuestra Constitución ha elevado también a valor jurídico fundamental la dignidad de la persona, que, sin perjuicio de los derechos que le son inherentes, se halla íntimamente vinculada con el libre desarrollo de la personalidad... Del sentido de estos preceptos puede deducirse que la dignidad es un valor espiritual y moral inherente a la persona, que se manifiesta singularmente en la autodeterminación consciente y responsable de la propia vida y que lleva consigo la pretensión al respecto por parte de los demás» (STC, 11-4-1985, F. J. 8). 
habitual ${ }^{31}$. Este doble anclaje de la conciencia en una necesaria duplicidad relacional, determinada por la concreción de la historia y la trascendencia de la razón o el espíritu, es el ámbito necesario donde ha de descubrirse y realizarse la verdad del hombre, conciliando e integrando la propia vida con la verdad personal, común a todo ser humano. Individualidad, libertad y la búsqueda de valores en el propio ser, debidamente relacionadas e integradas, conforman la esencia de la conciencia personal.

Probablemente, uno de los errores más graves del idealismo consistió en identificar o confundir la conciencia con el puro pensamiento o con la desnuda racionalidad, reconociendo, de forma exclusiva, su expresión más perfecta en el hecho del conocimiento objetivo al margen de cualquier influencia de la sensibilidad humana, tanto física como psicológica o afectiva. Según esta corriente filosófica, la conciencia habría de ser considerada, ante todo, como un ensimismamiento y una reflexión de la vida sobre ella misma, siempre, bien entendido, en el ámbito exclusivo de su esfera individual. Esta concepción, sin embargo, pasa por alto el hecho innegable de que la conciencia permanece la misma e idéntica a sí misma dentro de la más plural diversidad de sus manifestaciones. Cualquier circunstancia, acontecimiento o sentimiento, por inmenso e impactante que parezca, siempre resulta parcial y mínimo respecto a la totalidad del ser humano, porque siempre es el ser humano completo, en su totalidad e individualidad concreta y única quien se reconoce idéntico a, único y consciente de sí mismo.

Ser consciente o tener conciencia no es algo distinto a poseerse, a saberse, sentirse y percibirse uno y dueño de sí; o lo que es lo mismo, a controlar y garantizar la unidad interior y su expresión exterior, en dinamicidad o contemplación, de una individualidad esencialmente constituida en organicidad (materialidad-pluralidad-diversidad) y espiritualidad (unidad-sobrenaturali-

${ }^{31}$ Resulta ilustrativo, a este respecto, el célebre pasaje del Simposio en el que Diotima, explicando a Sócrates la naturaleza del eros, se refiere a la unidad-conciencia del hombre, aclarando y explicitando que la unidad humana no sólo acontece en el cuerpo, sino también en el alma, en el interior del hombre, desde el momento en que comportamientos, hábitos, opiniones deseos, placeres, dolores y miedos cambian continuamente en la misma e idéntica persona. Ni siquiera los conocimientos escapan a esta ley. Sólo el estudio y la reflexión, que generan recuerdos que ocupan el lugar de los desaparecidos, salvan la unidad de nuestro conocimiento de modo que siempre parezca el mismo: «... la naturaleza mortal busca, en la medida de sus posibilidades, de existir siempre y de ser inmortal... De hecho, también en el tiempo en que cada uno de los seres vivientes se dice que vive y que es el mismo (to auto), como por ejemplo de un hombre se dice que es el mismo desde que es niño hasta que es un anciano, y se dice que es el mismo aun cuando, en realidad, no mantenga en sí mismo las mismas cosas, sino que se renueva continuamente, e incluso pierde algunas cosas, en sus cabellos y en la carne y en los huesos y en la sangre y en todo lo que conforma su cuerpo... [Y, por lo que se refiere a los conocimientos] no puede decirse que sea el mismo, como acontece en la divinidad, sino que, en lugar de lo que desaparece o envejece, se coloca aquello que de mayor juventud es semejante a lo anterior» (Simposio 207 C - 208 B). 
dad-transcendencia). La conciencia, pues, no puede reducirse ni a puro conocimiento, ni puede identificarse con la causa de lo que somos, sino que, en cuanto reducto último de nuestra existencia, podría considerarse como la dimensión personal última por la que nosotros sabemos que somos y cómo somos.

Entenderemos, pues, por conciencia, siempre desde una perspectiva prevalentemente ontologista y operativa, por cuanto respecta al objetivo de esta reflexión, lo que resta de específica y fundamentalmente personal cuando el hombre se ve despojado de todo, es decir, el ámbito o realidad donde el hombre puede reconocerse como sí mismo y sentirse, respecto a sí mismo y en relación a los otros, como único y diverso a los demás. $\mathrm{O}$ dicho de otro modo, conciencia sería equivalente a persona en cuanto desnudo sujeto de relaciones intra e interpersonales y, en este sentido, expresaría o definiría a la persona en su más íntima esencia y, consecuentemente, en su más profunda debilidad. Al referirnos a la conciencia en su dimensión relacional intra e interpersonal asumimos una conceptualización abierta que trasciende y supera el ámbito de la simple e individualista privacidad.

Que la conciencia pueda ser definida como una relación íntima y privilegiada del hombre consigo mismo no es equivalente a su clausura en la trastienda de lo privado; antes al contrario, la conciencia, en cuanto fundamento último de la personalidad individual, ha de expresarse y manifestarse necesariamente en la actuación y proyección social del hombre. Más, la relación que en el foro de la conciencia establece el hombre consigo mismo ha sido, más allá de la influencia que hayan supuesto el humanismo o el iusnaturalismo iluminista, la causa última que ha llevado a plantearse a fin del siglo XX una imagen secularizada de la conciencia convertida, no sólo desde el derecho constitucional sino incluso desde la filosofía y la antropología, en principio trascendental y autónomo, creador de la libertad de pensamiento y de la libertad religiosa. Por otra parte, el hecho de que se reconozca a la conciencia como lugar en que adquiere toda su fuerza y potencialidad la exigencia y reivindicación de los derechos de la persona comporta e implica no sólo su nítida e inequívoca desprivatización, sino su necesaria «juridización» ${ }^{32}$.

\footnotetext{
${ }^{32}$ Esta necesaria relación de fundamentalidad entre conciencia y derechos conduce a la pregunta sobre quién o qué habrá de delimitar, definir o señalar las pautas y modos de relación, así como la jerarquía y circunstancias en que una y otros han de articularse. Es decir, cuando invocamos la virtualidad o fuerza jurídica de la conciencia, ¿estamos refiriéndonos a la manifestación de, o adecuación a, un orden moral objetivo; o, por el contrario, nos movemos en la diversidad de las decisiones subjetivas ancladas en principios trascendentes o trascendentales, o bien en opciones de anarquía ética? No es momento de entrar directamente en esta problemática, cuyo tratamiento excede los límites fijados a esta reflexión, puesto que el interrogante planteado exige el riesgo de una teoría general tanto de la conciencia como de la libertad de conciencia; pero tampoco cerramos esta senda a nuestra futura reflexión sobre esta temática, máxime cuando, según nuestra opinión, la respuesta a la pregunta formulada constituye el nudo gordiano, a través de la conciencia y de sus implicaciones jurídicas, del verdadero respeto a los derechos fundamentales de la persona y efectiva
} 


\section{Breve acercamiento a algunos planteamientos confesionales}

En relación con los problemas más graves e importantes que actualmente se plantea la bioética, al menos por lo que se refiere a aquellos que más directamente afectan a la vida del ser humano y a su conservación, todas las confesiones cristianas coinciden en situar y proponer a la persona humana como centro, fundamento, razón de ser última y, en consecuencia, límite de la experimentación científica en todo aquello que afecta a la persona en su esencia y dimensión de humanidad. De este modo, el respeto a la persona, y a su conciencia, tanto en sentido jurídico como ético o psicológico, así como la promoción de su desarrollo y perfeccionamiento se asumen, por parte de estas confesiones, como criterio definitivo de constraste moral a la hora de enjuiciar la licitud de acciones o decisiones vinculadas con el mundo de la medicina, la genética, la reproducción, la salud e incluso todo aquello que, relacionado con las ciencias de la naturaleza, afecte directamente al ser humano.

También las demás religiones monoteistas asumen idénticos principios sobre todo en aquellas cuestiones que ellas entienden directamente relacionadas con el ser humano y con su dimensión de criatura divina por excelencia. Es decir, no se trataría sino de respetar el plan de Dios que se concreta en el reconocimiento del valor absoluto de la persona. Del mismo modo que aceptan, y en tantas ocasiones impulsan, la investigación así como la creación y utilización de medios que favorezcan, protejan, amplíen y profundicen el bienestar de la persona humana, rechazan, por inmorales, todas y cada una de las intervenciones que, según ellas, trastocan o modifican el plan divino sobre los hombres: ni el aborto, ni la eufemísticamente denominada eutanasia, ni la manipulación genética, ni el ensañamiento pseudovitalista con enfermos sin remedio, ni aquellos tipos de fecundación artificial en que, según ellas, se altera sustancialmente el ritmo natural de la generación humana, etc. pueden esperar acogida en unos principios éticos que, aunque formalmente no tengan un primordial carácter religioso, se fundan en concepciones antropológicas y cosmológicas en que la centralidad de la persona y el plan de Dios han de situarse siempre por encima de cualquier veleidad y ansia desmedida de poder y dominio humano.

protección de su ejercicio. Para una aproximación a la aplicación de este concepto de conciencia a la problemática relacionada con el derecho a la salud puede verse el acertado planteamiento que realiza S. TARODO SORIA, Libertad de conciencia y derechos del usuario de servicios sanitarios (Bilbao 2005), 12-25, así como el clarificador y profundo estudio realizado por M. A. AsENSIO SÁNCHEZ, La patria potestad y la libertad de conciencia del menor. El interés del menor a la libre formación de su conciencia (Madrid 2006), 115-133, por cuanto respecta, en general, a la situación jurídica del menor. 


\section{1) El pionero magisterio de la Iglesia Católica}

$\mathrm{Si}$, como se ha expuesto anteriormente, se considerase la bioética como una especialidad dentro del género ética y se asumiera, como ya hemos señalado que defienden algunos, que aun cuando el término se acuñara a principios de los años setenta del siglo pasado, sin embargo, ya con anterioridad la preocupación por los problemas de carácter bioético estaba muy presente en la sensibilidad social, podríamos asegurar que el magisterio de la Iglesia Católica, sobre todo en y a partir del papa Pío XII, fue pionero en esta materia.

Indicio indiscutible y revelador de la preocupación e interés con que desde la ciencia y el pensamiento católicos se sigue todo lo relacionado con la bioética y sus planteamientos es la existencia de Cátedras o Institutos de Bioética en la mayoría de las Universidades Católicas y en casi todas las Facultades de Teología, dentro de los Departamentos de Ética o de Teología Moral: cada curso académico se cuentan por decenas los títulos de tesis doctorales o tesinas de licenciatura que tienen por objetos temas relacionados con la bioética. Los límites de este género académico nos impiden el análisis detallado de las abundantes (34 alocuciones, la última cinco días antes de su muerte y varios mensajes radiofónicos) y profundas enseñanzas de Pío XII sobre problemas y asuntos que hoy se consideran fundamentales y comunes en bioética, más allá, por supuesto, de las discrepancias científicas a la hora de determinar su origen, metodología e incluso el alcance de sus contenidos. Con no pocas reservas, por la dificultad de la misión, nos atrevemos a señalar, a modo orientativo, las siguientes intervenciones del Papa Pacelli:

- Alocución a los participantes en el Cuarto Congreso Internacional de Médicos Católicos [Roma, 29/09/1949] (Acta Apostolicae Sedis [AAS] 41, 1949, 557-561).

- Ídem a los participantes en el Congreso de la Unión Católica Italiana de Comadronas [Roma 29/10/1951] (AAS 43, 1951, 835-854).

- Ídem a los participantes en el Quinto Congreso Internacional sobre psicoterapia y psicología [Roma, 13/04/1953] (AAS, 45, 1953, 278286).

- Ídem a los asistentes al Primer Simposio Internacional de Genética Médica [Roma 07/07/1953] (AAS, cit., p. 596-607).

- Ídem a los asistentes al Vigésimosexto Congreso de la Sociedad Italiana de Urología [Roma 08/10/1953] (AAS, cit., p. 673-679).

- Ídem a los asistentes al Congreso Latino de Radiología y Electromagnetismo, así como al de Radiología Médica de la Asociación Italiana [Roma 04/04/1954] (AAS 46, 1954, 214-218).

- Ídem a los Miembros de la Pontificia Academia de Ciencias [Roma 24/04/1955] (AAS 47, 1955, 394-401).

- Ídem a los participantes en el Congreso Mundial celebrado en Nápoles sobre la fecundidad y esterilidad humanas [Roma 19/05/1956] (AAS 48, 1956, 467-474). 
— Ídem a los asistentes al Cuarto Congreso de la Asociación Italiana de Quimioterapia [Roma 06/10/1956] (AAS, cit., p. 793-797).

- Ídem a los asistentes al Séptimo Congreso Internacional de la Sociedad Internacional de Hematología [Roma 12/09/1958] (AAS 50, 1958, p. 732-740).

El magisterio de la Iglesia continúa, bajo la huella de Pío XII, la elaboración y proposición de una amplia y abundante doctrina de hondas raíces bioéticas. No de otro modo pueden leerse, por ejemplo, los documentos del Concilio Vaticano II, de forma especial la Constitución Pastoral Gaudium et Spes, cuando exponen su concepción del hombre y de la familia (AAS 58, 1966, p. 1067-1074); la Encíclica Humanae Vitae, de 25 de julio de 1968 (AAS 60, 1968, 481-503); la Declaración De abortu procurato de la Congregación para la Doctrina de la Fe, de 18 de noviembre de 1974 (AAS 66, 1974, 730-747); la Declaración De quibusdam quaestionibus ad sexualem ethicam spectantibus, de 29 de diciembre de 1975 (AAS 68, 1976, 77-96); la Carta a los obispos sobre La sterilizzazione negli ospedali cattolici, de 13 de marzo de 1975; la Declaración de la Congregación de la Doctrina de la Fe De Euthanasia [Jura et bona], de 5 de mayo de 1980 (AAS 72, 1980, 542552); la Exhortación Apostólica Familiaris Consortio, de 22 de noviembre de 1981 (AAS 74, 1982, 81-191); la Instrucción De observantia erga vitam humanam nascentem deque procreationis dignitate tuenda [Donum Vitae], de 22 de febrero de $1987^{33}$ (AAS 80, 1988, 70-102). Finalmente, del largo pontificado de Juan Pablo II, cabe destacar las importantes referencias que el

${ }^{33}$ La conclusión de este documento reviste, a nuestro entender, un especial interés no sólo por lo que dice, sino, quizás y sobre todo, por los cauces de esbozada novedad metodológica que apunta: «[En este documento se intenta]... novam igitur adhortationem, sollicitudinis plenam, ad eos omnes dirigit qui, pro sua quisque parte atque officio, efficacem operam praestare possunt ut in familia atque in societate debita tirbuatur observantia vitae atque amori: ad eos scilicet, quibus munus incumbit conscientias et publicam opinionem formandi; ad eos qui scientiam scolunt et medicinam exercent; ad iuris peritos, et ad rei politicae addictos. Quibus omnibus ipsa exoptat, ut intellegant nullo modo componi posse agnitionem dignitatis personae humanae cum vitae et amoris contemptu, atque fidem in Deum vivum cum arroganti proposito de ortu ac sorte creaturae humanae ad arbitrium decernendi.

«Peculiari modo Congregatio pro Doctrina Fidei cum fiducia invitat atque instimulat theologos, ac nominatim moralis doctrinae cultores, ut quae de hac re a Magisterio Ecclesiae docentur, altius ea investigent ac magis magisque captui christifidelium accommodent, sub lumine sane doctrinae anthropologicae in re sexuali et matrimoniali, ac necessaria inter varias disciplinas relatione servata. Poterunt ita melius percipit huius doctrinae argumenta ac robur: Ecclesia Dei, cum defendit hominem contra suae ipsius potestatis abusum, simul eum commonefacit, quae sint verae suae nobilitatis rationes; tantum hoc modo futurae hominum communitati facultas praebetur vivendi et amandi in iis dignitatis ac libertatis condicionibus, quae a veritatis obsequio proficiscuntur. Definitae igitur agendi rationes, quae per hanc Instructionem impetiuntur, minime intendunt investigationum nisus cohibere, sed potius renovatum earum studium excitare, necessaria erga Ecclesiae doctrinam fidelitate servata» (p. 101) 
papa realiza a cuestiones directa o indirectamente relacionadas con la bioética en la Veritatis splendor, de 6 de agosto de 1993 (AAS 85, 1993, 11331228) y, sobre todo, la encíclica Evangelium vitae, de 25 de marzo de 1995 (AAS 87, 1995, 401-522), en la que, por primera vez se usa el término bioética en un documento magisterial pontificio y además se afrontan directamente los problemas más candentes de esta disciplina.

\section{2) Fundamentos 'bio-teológicos' de las religiones monoteístas}

Las tres grandes religiones monoteístas parten, en todo lo referido con la vida en general y la humana en particular, del axioma de la creación divina: todo lo que existe ha brotado de las manos de Dios y nada de lo llamado a existir es ajeno al designio de la voluntad divina, al margen y más allá de los matices con que en determinadas cuestiones se interprete el ex nihilo. Dios, pues, es fuente única y primordial de la vida y Él, por tanto, es reconocido como único dueño y señor de ella: el hombre es su agraciado depositario. La creencia en la resurrección y en el juicio divino con premio y castigo aparece necesariamente como colofón indiscutible de esta necesaria relación del hombre con su Creador.

Para la religión hebrea, el hombre es la criatura predilecta de Dios por haber sido creado por el mismo Dios a su imagen y semejanza: «El hombre es predilecto de Dios porque ha sido creado a su imagen; porque se le ha manifestado un amor especialísimo al haber sido creado a su imagen» ${ }^{34}$. De este ser imagen de Dios derivan la dignidad humana, su misión en el mundo y la historia y el hecho de que para Dios todos los hombres sean iguales: «Dios creó un solo ser humano para enseñarnos que si uno destruye a una persona, la Escritura lo considera como si hubiese destruido el mundo entero; y si uno salva una vida, la Escritura lo considera como si hubiese salvado el mundo entero ${ }^{35}$. La propia Mishnàh insiste en la radical y específica unicidad y singularidad del ser humano, fundadas y, al mismo tiempo, derivadas del propio acto creacional: «La grandeza del Santo, que sea por siempre bendito, se desvela de este modo: cuando un hombre acuña muchas monedas con un solo troquel [molde], todas ellas resultan exactamente iguales; por el contrario el Rey de reyes, el Santo, que sea por siempre bendito, ha hecho a cada hombre con el molde utilizado para el primero y, a pesar de ello, ninguno es igual a otro. Por tanto, todos y cada uno de los hombres pueden afirmar: el mundo ha sido creado para mí».

Esta semejanza del hombre con Dios le muestra, a su vez, cuál ha de ser la razón y sentido de su vida. El hombre debe tender a ser semejante a Dios en sus acciones, pero nunca debe pretender ser como Dios (Gen 3, 5), sino

\footnotetext{
${ }^{34}$ Mishnàh Abot III, 15 y Gen. 1, 27.
}

${ }^{35}$ Mishnàh Sanhedrín IV, 5. 
que el proceso de asimilación a su Dios se resume, para el hebreo, en el repetido precepto que figura en el Levítico: «Sed santos, porque Yo, el Señor, Dios vuestro, soy santo» (Lev 19, 2). El servicio debido a Dios debe animar y traspasar toda la existencia humana. Es más, el hecho de que en la Biblia no exista distinción alguna entre las prescripciones que se refieren a las relaciones interhumanas y las que afectan a las relaciones entre el hombre y Dios pone en evidencia sin ningún género de duda que ambas trayectorias de la relación humana derivan de la voluntad de Dios. En la Toràh, decisión moral y opción religiosa aparecen íntima e indisociablemente unidas. Se trata, en definitiva, de la realización de Dios en la experiencia humana. El ser humano, pues, se distingue de las demás criaturas porque, al haber sido creado a imagen de Dios, es capaz de elegir entre el bien y el mal, entre la rectitud y el pecado, entre obedecer y desobedecer: «Mira que pongo ante ti la vida y el bien, la muerte y el mal» (Dt 30,15).

También para la teología cristiana el Antiguo Testamento presenta al hombre como la obra más importante del Creador ${ }^{36}$. A causa de su semejanza divina el hombre se distingue esencialmente del resto de la creación, pero, a pesar de ello, no es nada por sí mismo ${ }^{37}$ y sólo es en la medida en que reconoce su dependencia de Dios ${ }^{38}$. Tanto la vida física del ser humano como su psique y afectividad residen indistintamente en el alma o en el espíritu, en la carne o en el corazón ${ }^{39}$, incluso la actividad intelectual y las decisiones de la voluntad vienen atribuidas de forma especial al corazón ${ }^{40}$.

Los Evangelios sinópticos parten de una imagen y concepción extremadamente claras y precisas del hombre: es el ápice de la creación, su perfecto cierre, en el que Dios manifiesta especialmente su amor y su cuidado y predilección ${ }^{41}$; ha sido creado para dar gloria a Dios y producir frutos de salvación ${ }^{42}$.

${ }^{36}$ Cf. Gen 1, 1-2, 4; 2, 4b-7 y Sal 8, entre las muchas citas que se podrían aportar.

${ }^{37} \mathrm{Cf}$. Is $2,22$.

${ }^{38}$ Cf. Gen $3,8-11$ y $4,9-14$

${ }^{39}$ Cf. Jue 16, 5; I Sam 25, 37; Sal 21 [22], 27; etc.

${ }^{40}$ Cf. Ex 31, 6; I Sam 14, 7; etc.

${ }^{41}$ Cf. Mt 6, 26-30; 10, 29-31; etc.

${ }^{42} \ll \ldots$ en el pensamiento cristiano de todos los tiempos y de todos los lugares, el leit motiv del hombre como imagen de Dios, imagen de Cristo, es el planteamiento de fondo de una 'imitación', que es también una 'vida en Cristo en el Espíritu Santo', o sea, el camino que va de la imagen a la semejanza... [se trata de] la historia del amor loco de Dios quien cuando 'dice', 'hace' al hombre, revelando ya así al que vendrá como Palabra Encarnada, a cuya imagen el hombre descubrirá que ha sido creado. Decir el hombre es decir Cristo. Palabra pronunciada como amor y con amor, el hombre camina en la creación siguiendo las huellas de la relación que lo crea Imagen de la Relación y de la Comunión trinitaria. Decir el hombre es atreverse a decir la Trinidad... Por eso, la Revelación, Cristo como Persona Divinohumana, es sinónimo de historia de la salvación, puesto que cada vez que la imagen (el hombre) descubre su belleza y su origen se le quita el velo del ofuscamiento de Adán, pero sin agotar nunca el Misterio de su Imagen primordial. Cristo revela y a la vez oculta en la cruz la bondad de Dios, ese rostro inclinado sobre la criatura que lo podrá reflejar de nuevo, 
Según la antropología coránica el hombre ocupa un lugar privilegiado, muy por encima de todas las demás criaturas, en los planes de la creación divina, puesto que el hombre es el único representante de Dios sobre la tierra: los propios ángeles, por orden divina, están debajo del hombre. El Islam funda la dignidad del hombre no en el hecho de que el hombre haya sido creado a imagen y semejanza de Dios, puesto que Dios no puede ser semejante a nada ni a nadie, sino que aquella está directamente relacionada con la misión divina que el hombre debe llevar a cabo sobre la tierra, así como con la gracia que el hombre recibe de Dios para llevarla a buen término ${ }^{43}$.

\section{3) El trasunto práctico de los principios teológicos}

A partir de esta realidad fundamental se articulan las respuestas que las religiones monoteístas ofrecen ante los grandes retos o propuestas a que se enfrenta la bioética. Excedería los límites de nuestro propósito en esta sede intentar una siquiera pequeña muestra de la enseñanza de las distintas confesiones religiosas en torno a todos los problemas fundamentales de la bioética $^{44}$. Y ello aunque lo abordáramos con la máxima brevedad. Vamos, pues,

recibiendo el Espíritu, o sea el amor, y así, amando con el mismo amor, podrá de nuevo reflejar el mismo esplendor, revelar a su vez la misma gloria... La creación, la salvación, la 'deificación' del hombre, se realiza 'por el Padre por medio del Hijo en el Espíritu Santo', según una de las fórmulas trinitarias más antiguas» (O. ClémENT, Introducción, en M. I. RUPNIK, Decir el hombre. Icono del Creador, revelación del amor, Madrid 2000, 5 y 6-7). Cf. Mt 5, 16; 7, 17-20; Lc 13, 6-9; 17, 7-11; etc.

${ }^{43} \mathrm{Cf}$. A. FALATURI, Die Bedeutung des islamischen Menschenbildes für die Erziehung, en J. LÄHNEMANN (ed.), Erziehung zur Kulturbegegnung (Hamburgo 1986), 43-50; H. LuDIN-JANSEN, «Zur Frage vom Menschenbild im Koran», Temenos. Studies in comparative religion 16, 1980, 56-61; Maнома (Munammad), Le parole del Profeta, ed. de Abdullah al-Mamun alSuhrawardy (Roma 1997); T. NAGEL, Zum Menschenbild in modernen Islam, en 19. Deutscher Orientalistentag in Freiburg 1975 (Wiesbaden 1977), 559-566; A. M. DI NolA, Maometto. La saggezza dell'Islam (Roma 2001), 35-62; IDEM, L' Islam. Storia e segreti di una civiltà (Roma 2004), 65-166; A. Schimmel, «Zur Anthropologie des Islam», Anthropologie religieuse 2, 1955, 140-154 [Supl.]; M. TworusCHKA, Islam (Gotinga 1982), 43-51.

${ }^{44} \mathrm{Al}$ margen de su posibilidad de tratamiento, sobre todo por las razones aducidas, hemos de dejar constancia, por su actualidad e incidencia social, de la importante problemática derivada de la investigación sobre células-madre obtenidas de embriones humanos, de los casos planteados por la práctica de xenotrasplantes o trasplantes transgénicos, de los supuestos de venta voluntaria de órganos por parte del donante, de los interrogantes a los que en determinadas circunstancias extremas se enfrenta el médico aun cuando exista testamento vital previo, etc. Como recientemente confesaba un experimentado cirujano, «... alla fine... promisi a me stesso che da quel momento in poi, testamento biologico o meno, avrei approfondito con maggiore chiarezza, con ogni singolo paziente, tutti i rischi di un percorso clinico che a volte può celare insidie inaspettate... L'esistenza di direttive anticipate scritte dal paziente stesso costituiscono un supporto straordinario in momenti decisivi come quelli relativi a un'eventuale interruzione delle terapie. Tale strumento tuttavia non deve essere rigido e il medico deve mantenere la propria libertà di giudizio per valutare quando è il caso 
a mostrar, sin ánimo de exhaustividad como ya se ha señalado, la postura moral de estas grandes religiones sobre algunas de las cuestiones a que hoy se enfrenta la bioética.

\section{a) FECUNDACIÓN ARTIFICIAL ${ }^{45}$}

Sólo la inseminación artificial homóloga, es decir, la intracorpórea entre esposos es admitida como éticamente lícita por la moral católica y ello siempre que se utilice como ayuda a la procreación. A pesar de la diversidad de comunidades e Iglesias protestantes, cabe afirmar que la gran mayoría de los reformados aceptan los métodos artificiales de reproducción humana siempre que las células germinales sean propias de los miembros de la pareja (fecundación homóloga), rechazándose en general aquellos métodos que implican la fecundación heteróloga.

Al igual que en el caso de las anteriores, la moral hebrea sólo permite la utilización de técnicas reproductivas artificiales cuando el óvulo es fecundado con esperma del esposo (homóloga), rechazándose cualquier otro método en razón de los problemas que se plantearían tanto respecto a la unidad del matrimonio como respecto a la propia identidad y pertenencia familiar del hijo $^{46}$.

A semejanza de lo que ocurre con las Iglesias reformadas, también resulta difícil ofrecer una doctrina única y generalizada en el caso del Islam, dada su estructura social, política y religiosa, así como la autonomía de las distintas comunidades; sin embargo, se puede afirmar, sin riesgo de error, que la ética islámica sólo acepta la intervención artificial en la concepción cuando, para paliar la esterilidad de la pareja, se recurre a la fecundación homóloga, rechazando como ilícita la heteróloga por considerarla en realidad como un verdadero adulterio, si bien, como ya formuló hace años un ilustre canonista español, se trataría de un adulterio casto $^{47}$.

di proseguire le terapie e quando invece è più giusto fermarsi, evitando un accanimento che non rispetterebbe la dignità del paziente» (I. R. MARINO, Credere e curare, Turín 2005, 60 y 63). La cursiva es nuestra.

45 «... al contrario di molti anni fa quando ci si interrogava sulla possibilità di eliminare un embrione, ora si dibatte su quale sia il modo lecito per creare una nuova vita ricorrendo alla fecondazione medicalmente assistita» (I. R. MARINO, Credere..., cit., p. 45).

${ }^{46}$ Cf. R. DI SEGNI, Il punto di vista ebraico su aborto, contraccezione e fecondazione artificiale, en L. BIAGI y R. PEGORARO, Religioni e bioetica. Un confronto sugli inizi della vita (Padua 1997), 291-294.

${ }^{47}$ Cf. T. García Barberena, «Adulterio casto», Revista Española de Derecho Canónico 19, 1962, 72-81; A. Guessous, La procreación artificial: un punto de vista islámico, en AA VV, Proyecto genoma humano: Etica (Bilbao 1991) 141-145; F. BEN HAMIDA, Islam y Bioética, en AA VV, La salud y los Derechos Humanos. Aspectos éticos y morales (Washington 1990) 74-76. 
Todas ellas rechazan como ilícito el recurso a la maternidad sustitutiva, con la única excepción de algunas escuelas jurídicas islámicas que la aceptan únicamente en el supuesto de que la madre portadora sea alguna de las esposas legítimas del marido. Por otra parte, dada la complejidad que presenta en la actualidad todo lo referido con las técnicas de reproducción asistida, quizás habría de tomarse en consideración, tanto desde el derecho como desde la ética, las opciones y perspectivas razonables que la ciencia propone ${ }^{48}$.

\section{b) $\mathrm{ABORTO}^{49}$}

Aun cuando las tres grandes religiones monoteístas reconocen a Dios como creador y señor de la vida, sin embargo difieren en su valoración ética del aborto en razón de la postura adoptada sobre el momento de la gestación en que se puede afirmar que existe verdadera y auténtica vida humana ${ }^{50}$.

48 «Proprio su questo argomento si troverebbe forse un accordo se si aprisse un dialogo costruttivo tra scienza e religione. Tutti, infatti, ammettono che in passato è stato fatto un errore nel creare decine di migliaia di embrioni umani che ora esistono e attendono solo di spegnersi nel freddo nei frigoriferi delle cliniche per l' infertilità. La loro fine è certa, ma è meglio lasciarli morire oppure utilizzare le loro preziose cellule per scopi di ricerca? Per chi è cattolico si tratta di vite e come tali non possono essere soppresse, ma può darsi che la scienza, ancora una volta, ci possa venire in aiuto. Si potrebbe forse individuare il momento in cui un embrione perde la capacità di molteplicare le sue cellule, cioè la possibilità riproduttiva, e non può più essere utilizzato per dare origine a una vita. A quel punto, con un meccanismo simile a quello previsto per la donazione degli organi di un paziente in morte cerebrale, gli embrioni potrebbero essere donati ai laboratori di ricerca.

«Si potrebbe pensare di elaborare, su basi scientifiche, la definizione di 'morte riproduttiva' cosí come è stato fatto con il concetto di 'morte cerebrale'...», aunque también se ha de tener siempre muy presente que «oggi nessuno è in grado di assicurare che la ricerca sulle terapie con le staminali estratte attraverso la distruzione di un embrione avrà l' impatto rivoluzionario auspicato. Per questo è necessario che anche gli uomini di scienza agiscano con prudenza: è inutile e immorale promettere ai cittadini certezze che, al momento, sono soltanto supposizioni» (I. R. MARINO, Credere..., cit., pp. 47-48).

${ }^{49}$ Se viene aceptando, tanto desde la ciencia médica como desde la ética y el derecho que la interrupción voluntaria del embarazo acaece en los siguientes supuestos: a) aborto terapéutico o realizado para salvaguardar la vida de la madre seriamente amenazada; b) aborto eugénico, denominado así porque tiene lugar en aquellos supuestos en que se prevé que el nuevo ser nacerá afectado por graves anomalías de carácter físico, psíquico o mental; c) aborto ético, practicado en aquellos supuestos en que el embarazo es consecuencia de la comisión de un delito, por ejemplo, una violación; y d) aborto psicosocial, denominado así por la variedad y amplitud de las razones y motivos que puede llegar a justificarlo legalmente (Cf. J. GAFo FernándeZ, Bioética teológica, Madrid 2003, 181-184).

${ }^{50} \mathrm{Al}$ margen de esta cuestión, como recordaba recientemente un eminente cirujano, al plantear la objeción de conciencia por parte del médico a la práctica del aborto, no debe olvidarse nunca que el aborto es el desenlace de un fracaso: «L' aborto, da qualunque punto di vista lo si voglia guardare, è la storia di un fallimento e le donne che vi sono sottoposte, per scelta o per necessità, sono in grado di comprendere meglio di chiunque altro il motivo per cui un medico possa decidere di non praticarlo» (I. R. MARINo, Credere..., cit., p. 44). 
La Iglesia católica ha considerado siempre el aborto como un delito especialmente malicioso ${ }^{51}$. La afirmación del derecho a la vida del no-nacido, incluso en las situaciones más díficiles y dramáticas, es una constante en el magisterio reciente de la Iglesia católica ${ }^{52}$. También, y sobre todo por la rela-

${ }^{51}$ El canon 1398 del Código de Derecho Canónico establece la pena de excomunión latae sententiae para quien procura el aborto, si éste se produce. El Código de 1917, en el párrafo 1 del canon 2350, a semejanza del actualmente vigente, también establecía que «los que procuran el aborto, incluso la madre, incurren, si el aborto se verifica, en excomunión latae sententiae reservada al Ordinario...». Según doctrina de la Pontificia Comisión para la Interpretación Auténtica del Código de Derecho Canónico, el aborto no es sólo matar el fruto inmaduro del vientre, sino toda acción que de cualquier modo y en cualquier momento conduzca a su muerte. La pena afecta a todos los que intervienen en el aborto y no sólo a la madre que mata o hace matar a su hijo: «D. Utrum abortus, de quo in can. 1398, intelligatur tantum de eiectione fetus immaturi, an etiam de eiusdem fetus occisione quocumque modo et quocumque tempore a momento conceptionis procuretur. R. Negative ad primam partem; affirmative ad secundam» (AAS 80, 1988, 1818-1819), formalizando así un tipo delictivo mucho más amplio que el derivado de la norma codicial de 1917. En el Código PíoBenedictino se tipificaba el delito de aborto como la eyección violenta y, en consecuencia, provocada del vientre materno de un feto humano vivo que, por su insuficiente desarrollo, es decir, antes de los ciento ochenta días desde su concepción (por analogia con el canon $1115,2)$ no puede vivir separado de la madre. La doctrina canónica anterior a la constitución Apostolicae Sedis, de 12 de octubre de 1869, requería para que se consumase el delito de aborto que el feto estuviese animado, es decir, que estuviese dotado de alma humana. Según una opinión muy difundida entre los antiguos, el feto no está animado desde el momento de la fecundación, sino más tarde, cuando su cuerpo ha adquirido una cierta organización que solía fijarse en ochenta días para las mujeres y cuarenta para los varones. La Constitución mencionada zanjó la cuestión suprimiendo la distinción entre feto animado e inanimado. Así pues, para la mayor parte de la doctrina canónica no podría calificarse como aborto la craneotomía, la embriotomía y otras operaciones semejantes realizadas directamente con la intención de matar al feto, pues tales operaciones son distintas de la de abortar y habrían de ser calificadas, en principio, de homicidio, graduando su tipicidad según las circunstancias personales en que aquellas se realizaren. Además, dado que el delito exige intención dolosa, no cabía ni la figura del aborto indirecto ni del aborto preterintencional. A pesar, sin embargo, de la interpretación extensiva por la que se decanta la Pontificia Comisión de Intérpretes, a la hora de fijar la existencia del delito y la irrogación de la pena se han de tener presentes las excepciones previstas en el canon 1323 del vigente Código de Derecho Canónico.

52 «La sacralità della vita è uno dei capisaldi della religione cattolica e di molte altre religioni e filosofie. Per questo è naturale che la Chiesa si sia sempre mostrata molto attenta nell' affrontare le tematiche che riguardano l' origine e la fine della vita. L' attegiamento prudenziale secondo cui l' embrione debba essere trattato come persona umana, dato che nel momento in cui l' ovulo è fecondato si inaugura una nuova vita, risale già a una dichiarazione della Chiesa del 1974, ripresa poi in un' istruzione del 1987 firmata dall' allora cardinale Joseph Ratzinger, Donum vitae, seguita nel 1995 dall' enciclica di papa Giovanni Paolo II Evangelium Vitae.

«Sulla base di questi due documenti fondamentali, la posizione della Chiesa cattolica appare molto severa su tutto quello che riguarda la procreazione, comprese le tecniche di fecondazione assistita...» (I. R. MARINO, Credere..., cit., pp. 45-46). 
ción que pudiesen tener con las prácticas abortivas, la Iglesia se ha pronunciado en distintas ocasiones sobre la licitud moral de las técnicas de diagnóstico prenatal: se consideran lícitas cuando se realizan con absoluto respeto a la vida del feto y de la propia madre, evitando todo riesgo desproporcionado; y se valoran como totalmente ilícitas las que se realizan con finalidad abortiva.

Para los protestantes sólo puede calificarse como ético el aborto cuando es el único remedio necesario para salvar la vida de la madre. Siempre el derecho a la vida del no nacido prevalece sobre el derecho de la madre sobre su propio cuerpo. Las técnicas de diagnóstico prenatal son valoradas, en general, de forma negativa, sobre todo, al objeto de evitar posibles desviaciones eugenésicas ${ }^{53}$.

Para la moral judía el aborto sólo se admite en aquellos casos en que pueda correr peligro la salud de la madre. En estos supuestos, antes de proceder a la ejecución del aborto, se ha de contar con la opinión de una autoridad rabínica reconocida. En aquellas situaciones en que entran en conflicto la vida de la madre y la del feto, se opta por la vida de la madre con el único límite del momento del alumbramiento, momento en que la criatura se convierte en nefesh, es decir, en ser animado por la ruah Yahveh, instante en que ya no cabe la elección a favor de la madre ${ }^{54}$.

Influidos por las teorías sobre la animación a que hemos hecho referencia más arriba, los maestros del Islam han considerado siempre legal el aborto siempre que existiesen causas precisas y determinadas y se practicara dentro de los ciento veinte días después de la concepción. No faltan, sin embargo, juristas e intérpretes del Corán que rechazan y condenan el aborto en todas sus formas y condiciones, excepto cuando se halla realmente en peligro la vida de la madre ${ }^{55}$.

\section{c) EUTANASIA ${ }^{56}$}

Los pronunciamientos del magisterio de la Iglesia católica sobre los problemas en torno a la eutanasia son abundantísimos y están presentes en todos

${ }^{53} \mathrm{Cf}$. AA VV, La salud y los derechos humanos. Aspectos éticos y morales (Washington 1999), 319-322.

${ }^{54}$ Cf. R. DI SEGNI, Il punto di vista ebaraico..., cit., p. 281-285.

${ }^{55}$ Cf. D. Atighetchi, Islam, Musulmani e Bioetica (Roma 2002), 69-75; B. F. MussaLLAM, «Sexo y sociedad en el Islam», Revista Verde Islam, n. 8, 1998, 15-18.

${ }^{56} \mathrm{Al}$ margen de la diversidad de significaciones del término eutanasia, según el contexto y la intencionalidad en que se utilice, en esta exposición asumimos las dos acepciones del término más frecuentes y habituales en las cuestiones planteadas a la bioética. Tomamos la eutanasia, en un sentido amplio, como aquella acción u omisión que tiende a causar la muerte con la finalidad de eliminar el dolor: el sufrimiento convertiría a la vida, según la consideración social, en indigna de ser vivida, justificándose de este modo la provocación de la muerte. En sentido más estricto, entendemos por eutanasia cualquier intervención voluntaria encaminada a provocar la muerte de alguien que, por razones patológicas, está 
los ámbitos y niveles de la jerarquía eclesial. Para la doctrina y enseñanza católicas, la eutanasia es una gravísima violación de la ley de Dios, en cuanto que consiste, al margen de las circunstancias con que se pretenda revestir o disimular, en la eliminación deliberada, querida y buscada de una persona humana. Se considera, por tanto, la eutanasia como un crimen que ninguna ley humana puede legitimar o justificar.

Ahora bien, la moral católica sí reconoce el derecho de toda persona a morir con dignidad humana y cristiana; por ello, se estima moralmente lícita la renuncia a medios terapéuticos desproporcionados que únicamente conducen a la prolongación indebida de la agonía. Con todo, la Iglesia rechaza el uso de analgésicos hasta el extremo de anular la conciencia de la persona moribunda, en razón de que en este caso se priva al hombre de la posibilidad de, e incluso del derecho a, vivir la propia muerte, reduciéndolo a un estado de inconsciencia indigna del ser humano, pues, con frecuencia, con este proceder se busca, más que eliminar el posible sufrimiento al enfermo, evitar el malestar y embarazo de quienes se han de relacionar en momento tan crucial con el moribundo.

La vida humana, enseñan los protestantes, es don divino, obra de Dios que no sólo la crea, sino que la sustenta. También para ellos el mandamiento no matarás connota y presupone la absoluta inviolabilidad de la vida humana y la tajante prohibición de disponer de ella. En razón de ello, consideran la eutanasia activa como un acto condenable y rechazable en cuanto que supone la más vergonzosa degradación de la vida humana, además de abrir la posibilidad de situaciones aberrantes y manipuladoras de la perso$n a^{57}$. No se oponen, sin embargo, a la no iniciación o a la supresión, según el caso, de medios médicos artificiales cuando ya no tienen por objeto la sanación del enfermo y se dirigen exclusivamente a prolongar, sin más, la vida/sufrimiento del enfermo.

Partiendo de la distinción entre la lícita acción de aliviar el dolor y no alargar la agonía y la inadmisible actuación que tiende directamente a acortar la vida para evitar el dolor y el sufrimiento, insisten, a la hora de valorar la licitud ética de un determinado comportamiento, en la importancia de la motivación de las acciones así como del fin pretendido. Por ello, por ejem-

próximo a la muerte, a fin de poner término a sus sufrimientos. En cualquiera de los dos sentidos, la muerte se considera siempre como un bien, como el único medio para liberarse de un sufrimiento intolerable o de una vida que no se considera digna de ser vivida. No entramos, en este lugar, ni en la mera descripción de las denominadas eugenésica, económica, criminal o experimental, por ser consideradas como simples homicidios o asesinatos en los ordenamientos democráticos.

${ }^{57}$ Probablemente no sea ajena a este radical rechazo de las prácticas eutanásicas por parte de las comunidades protestantes la experiencia vivida en Centroeuropa durante los años del nazismo con sus científicas, avanzadas y progresistas, en criterio de sus promotores, prácticas eutanásicas. 
plo, aceptan la licitud del uso en enfermos terminales de fármacos que alivien o mitiguen el dolor, aunque de su uso se derive indirectamente al acortamiento de la vida del paciente ${ }^{58}$. Al igual que otras confesiones religiosas, tambien los protestantes defienden el derecho a la utilización de todos los cuidados médicos integrales hasta el momento de la muerte, rechazando siempre el encarnizamiento terapéutico.

Para los moralistas y juristas islámicos, la eutanasia se presenta como contraria a la aceptación y superación humana del sufrimiento y, en consecuencia, si se practicara impediría obtener el perdón final y último de Dios, lo que la convierte en acto moralmente ilícito. Así pues, toda acción dirigida a poner fin a la vida humana, aunque se realice a petición de la persona, está totalmente prohibida y se considera como homicidio voluntario. El Islam no sólo rechaza la eutanasia activa directa, sino que también se opone radicalmente a la eutanasia pasiva directa, en lógica consecuencia con su condena general de cualquier interrupción voluntaria de la vida del enfermo. Sí que, por el contrario, se admite la licitud de aquellos tratamientos que tienden a hacer más llevadera la agonía y a aminorar sus dificultades, ansiedades y dolores, aunque ello implique el acortamiento de la vida del paciente. Y, del mismo modo, se acepta la licitud de la suspensión del tratamiento, bien de fármacos o de medios instrumentales artificiales, o su no iniciación cuando se tiene la certeza de que no existe esperanza alguna de curación, pues se considera que los tratamientos médicos sólo son obligatorios cuando ayudan positivamente a la curación del enfermo. A su vez, la ley islámica permite la no aplicación de tratamientos médicos o farmacológicos inútiles, así como su interrupción cuando sólo tienden a retrasar una muerte inevitable, siempre con el consentimiento del propio enfermo terminal o de sus familiares, según los casos. Sí que se urge la obligación de mantener las curas ordinarias de hidratación y nutrición ${ }^{59}$.

Para la moral hebrea la defensa de la vida, en cualquier situación, es un deber religioso directamente expresado en la Torá (Dt 30, 19); por ello, es un imperativo legal y moral prolongar la vida lo máximo que se pueda, debiéndose poner todos los medios posibles para salvar la vida de cualquier enfermo. De cualquier modo, ante situaciones límite, se estima que debe corresponder a personas ajenas a los directamente afectados la toma de decisiones a fin de evitar todo riesgo de subjetivismo y para poder decidir con objetividad e imparcialidad. En consecuencia, la ley judía tradicional rechaza y prohíbe toda acción dirigida a provocar o acelerar la muerte del paciente,

${ }^{58}$ Cf. P. TARQuis Alonso, Bases teológicas de la ética protestante, en J. GAFo FernánDEZ (ed.), Bioética y religiones: el final de la vida (Madrid 2000), 60-64.

${ }^{59}$ Cf. D. ATIGHETchi, Islam, Musulmani e..., cit., p. 190-202; R. TATARY BAKRY, Islam, Bioética y final de la vida, en J. GAFO FERNÁNDEZ (ed.), Bioética y religiones..., cit., pp. 80-86. 
calificándola de asesinato, incluso la mitigación del dolor sólo se admite cuando no conlleve la provocación de la muerte ${ }^{60}$. Algunas autoridades o escuelas rabínicas estiman, aun contando con su valoración absolutamente positiva de la vida humana, que es lícito rechazar la prolongación de la vida por medios artificiales. Es importante señalar que cualquier decisión sobre el enfermo terminal exige la intervención de la Santa Fraternidad ${ }^{61}$ que, en caso de duda, ha de consultar a la autoridad rabínica correspondiente.

\section{d) El ENCARNIZAMIENTO TERAPÉUTICO (DISTANASIA)}

Constituye un tópico evidente el hecho de que la tecnología y el progreso científico actuales son capaces de prolongar artificialmente la vida de personas que, sin esperanza alguna de curación, no recuperarán jamás una condición aceptable de salud. Situación que irremediablemente enfrenta a médicos, familiares, moralistas y juristas ante el urgente dilema de la interrupción voluntaria de los tratamientos médicos ${ }^{62}$. Aunque la suspensión de todos aquellos actos que conforman el tratamiento médico conduce inevitablemente al fin de una existencia mantenida con vida artificialmente, por tratarse, en realidad, de la aceptación de un hecho natural, nos hallamos ante un supuesto completamente distinto al hecho de, por ejemplo, procurar directamente la muerte de una persona por medio de la administración de un determinado fármaco ${ }^{63}$.

${ }^{60}$ Cf. B. A. Garzón Serfaty, Judaismo y bioética, en J. Gafo Fernández (ed.), Bioética y religiones..., cit., pp. 115-122.

${ }^{61}$ Se trata de una institución de voluntariado compuesta por 18 miembros y que debe existir en cada comunidad judía. Su misión consiste en acompañar al enfermo en los últimos momentos de su vida, velando, además, porque se observen las prescripciones de la ley judía en las últimas fases del tratamiento médico. También entra en sus funciones la preocupación por la dignidad de las exequias tras la muerte, así como el acompañamiento y la atención a los familiares del difunto durante los días que dura el luto.

${ }^{62}$ En los Estados Unidos de América, por ejemplo, la interrupción de los tratamientos médicos, cuando no existe esperanza razonable de que el paciente pueda recuperar una condición aceptable de vida es una práctica habitual en los hospitales. Ahora bien, se trata de una posibilidad minuciosamente regulada por el ordenamiento y exquisitamente respetada por los profesionales de la sanidad. En la mayor parte de los casos, la decisión se adopta de común acuerdo entre médicos y familiares, salva siempre la situación que pueda derivarse de la existencia de testamento vital o biológico. Sin embargo, hemos de dejar constancia de que, a pesar de la existencia de tales prevenciones, no es infrecuente la existencia de conflicto en algunos casos.

${ }^{63}$ Hasta los años setenta, más o menos, se utilizaban todos los medios técnicos y mecánicos a disposición de los médicos para mantener con vida al paciente hasta que el corazón dejaba mecánicamente de latir, ejerciéndose sobre el enfermo un encarnizamiento terapéutico injusto e irrespetuoso con la dignidad humana. Las cosas comenzaron a cambiar en el año 1976 con el caso de Karen Quinlan, una mujer americana en estado vegetativo mantenida con vida gracias a un respirador automático. A petición de la familia, frente a la oposición 
La doctrina católica rechaza como no acorde con la dignidad humana la llamada obstinación terapéutica o, lo que es lo mismo, el empleo de medios extenuantes para el enfermo que, sin proporcionarle beneficio real alguno, sólo prolongan artificialmente su existencia. En caso, pues, de enfermedad terminal es totalmente lícito servirse únicamente de los medios normales y ordinarios que ofrece la medicina. Según la moral católica, el criterio que se ha de utilizar a la hora de decidirse por la continuidad en el mantenimiento de la vida de una persona no es otro que el de la distinción entre medios terapéuticos proporcionados y desproporcionados a la situación del enfermo: a los primeros no se debe renunciar, siendo lícita la renuncia a los segundos precisamente para no caer en el encarnizamiento terapéutico. Se suelen considerar desproporcionados aquellos medios y terapias en que las técnicas empleadas imponen al paciente sufrimientos y molestias superiores a los beneficios que puedan generar.

Los protestantes rechazan mayoritariamente el encarnizamiento terapéutico así como la prolongación artificial de la vida en circunstancias imposibles e inviables ${ }^{64}$.

También en el Islam se rechaza la distanasia, en razón de que el hecho de prolongar inútilmente las funciones fisiológicas vitales del enfermo va en contra del enfermo mismo y de su propia familia ${ }^{65}$.

La defensa de la vida hasta el último suspiro, radicada en el valor supremo e infinito de la vida humana para el judaismo, funda la prohibición de suspender los esfuerzos y medios dirigidos a prolongarla en cualquier circunstancia en que se encuentre el paciente. No obstante, la posición no es unitaria entre las autoridades rabínicas, pues mientras para unos la ley judía no permitiría ni la suspensión de tratamiento alguno ni la desconexión del enfermo terminal de los aparatos de los que depende, para otros sería totalmente legítima la eliminación de fármacos e instrumentos mecánicos que, de hecho, sólo sirven para prolongar el sufrimiento del paciente ${ }^{66}$.

de los médicos temerosos de poder ser perseguidos penalmente, la Corte Suprema de Nueva Jersey dio la razón a los familiares, precisando que si no existía una posibilidad razonable de que la paciente recuperase su integridad intelectiva debían serle retirados todas las máquinas y tratamientos de subsistencia y dejar que la mujer muriese en paz. Catorce años después, en 1990, el caso de Nancy Cruzan, en estado vegetativo, autónoma en la respiración, pero alimentada mediante sonda naso-gástrica, reabrió el debate de 1976. También en este caso se autorizó la suspensión del tratamiento y, como consecuencia, el Congreso se planteó la necesidad de reconocer como derecho de todo ciudadano la posibilidad de realizar el testamento vital.

${ }^{64}$ Cf. P. TARQuis Alfonso, Bases teológicas..., cit., pp. 62-65.

${ }^{65}$ Cf. D. Atighetchi, Islam, Musulmani..., cit., 187-189; R. TATARy BAKRY, Islam, Bioética..., cit., pp. 83-86.

${ }^{66}$ Cf. B. A. Garzón Serfaty, Judaismo y bioética..., cit., pp. 121-124; I. JaKobowits, Ebraismo, en S. SPINSANTI (ed.), Bioetica e grandi religioni (Milán 1987) 29-33 y 47-50. 


\section{Ante la vida y la muerte: ¿obstinación o diálogo?}

La sacralidad de la vida humana y su consecuente indisponibilidad por parte de la voluntad individual es el principio que mejor y con más precisión especifica y define las características o propiedades de lo que podríamos calificar, en orden a facilitar la metodología de su conocimiento, como bioética(s) confesional(es), a diferencia de la(s) que podríamos denominar como bioética(s) laica(s) o no confesional(es), para las que el principio fundante y regulador sería, por el contrario, el de la «calidad/cualidad de la vida» (quality of Live): no es la vida, en cuanto tal o en cuanto manifestación necesaria de un valor superior de orden religioso o metafísico, la que tiene la primacía, sino la calidad de vida, el bien estar, sólo la que tiene apariencia de «ser digna de ser vivida ${ }^{67}$.

En un cierto sentido, podría decirse que ésta sería una ética de lo adjetivo: no es el sustantivo vida el que determina la eticidad de un determinado acto, sino el modo, la calificación, de esa vida lo que se convierte en fuente de eticidad. Los partidarios de esta bioética, siguiendo a Séneca ( $« n o$ es un bien el vivir, sino el vivir bien» $)^{68}$, defienden que «la moral moderna no es, genéricamente, la moral de la vida. Es la moral de la vida feliz... la vida, como tal, no es un valor; sólo una vida que pueda decirse humana es un auténtico valor ${ }^{69}$. La aceptación, por principio, de que la vida es un valor sujeto a la libre disposición del hombre o, por el contrario, la proclamación de que ningún ser humano puede decidir sobre la vida, considerada como realidad suprema por encima de voluntariosos deseos o de circunstanciales conmiseraciones, sigue distinguiendo, en su fundamento, las bioéticas religiosas de aquellas que, en principio, se acogen exclusivamente al valor funcional de la inmanencia.

\section{1) Las posturas y sus perfiles}

Desde una perspectiva pedagógica adulta, quizás el mejor modo de poner el primer broche a esta exposición sea ofrecer el testimonio de distin-

${ }^{67}$ Cf. G. Fornero, Bioetica cattolica..., cit., pp. 22-128 y 153-177; A. SocCl, Il genocidio censurato. Aborto: un miliardo di vittime innocenti (Casale Monferrato 2006), 9-25, 3843 y $153-173$.

68 «...non enim vivere bonum est, sed bene vivere» (L. A. SÉNECA, [Literae] Ad Lucilum, vol. I, libro 8, carta 70 [ed. Rizzoli], Milán 1999, p. 447). Y, como aconteció en el propio Séneca, la desembocadura lógica de este principio es, en situaciones límite, el suicidio: cf. IDEM, De ira, 3, 15. Al contrario de lo que ya ocurría en el Cristianismo contemporáneo de Séneca: cf. G. Lombard, «L'Editto di Milano del 313 e la licità dello Stato», Studia et Documenta Historiae et Iuris 50, 1984, 26-28; C. MAZZucCO, Il significato della «libertas» proclamata dai martiri della «Passio Perpetuae», en Forma Futuri. Studi in onore del card. M. Pellegrino (Turín 1975), 542-565.

${ }^{69}$ U. SCARPELLI, Bioetica laica (Milán 1998), 91 y 131. 
tas personas o instituciones sobre una de las cuestiones más candentes en los planteamientos actuales de la bioética que continuamente llama a la puerta de juristas, legisladores, moralistas, antropológos y filosófos: me refiero a la eutanasia. Pues bien, he aquí seis testimonios... que cada uno juzgue:

Pertenece el primero a la Congregación para la Doctrina de la fe, de la Iglesia Católica:

«Nada ni nadie puede autorizar la muerte de un ser humano inocente, ya se trate de un feto o un embrión, un niño o un adulto, un viejo o un enfermo incurable o agonizante. Nadie, por otra parte, puede exigir este gesto homicida por sí mismo o por medio de otra persona bajo la responsabilidad de quien lo pide, ni puede consentir en ello ni implícita ni explícitamente. Ninguna autoridad puede legítimamente imponerlo o permitirlo. Se trata de hecho de una violación de la ley divina, de una ofensa a la dignidad de la persona humana, de un crimen contra la vida, de un atentado contra la humanidad»(Declaración sobre la eutanasia, n. 1).

El segundo es del Cardenal Martini, Arzobispo de Milán, jubilado actualmente:

«Como monstruosa aparece la figura de un amor que mata, de una compasión que borra y aniquila a aquel cuyo dolor no puede soportar, de una filantropía que no sabe ni puede explicar si pretende liberar a otro de una vida convertida exclusivamente en una carga o por el contrario liberarse a sí misma de una presencia que aparece sólo como una carga» («Omelia di Sant'Ambrogio», 1981, en D. TetTamanzI, Nuova bioetica cristiana, Cassale Monferrato, 2000, 544).

El tercero lo suscribe el Cardenal Tettamanzi, actual Arzobispo de Milán:

«Se trata [...] de asimilar por qué la eutanasia propiamente dicha se configura como un gesto monstruoso. El porqué está en el hecho de que la eutanasia contradice radicalmente el fundamental, intangible, irrenunciable valor de la vida humana como realidad 'sagrada'» (Nuova bioetica cristiana..., cit., p. 545).

El cuarto corresponde a uno de los varios Manifiestos sobre la eutanasia:

«Es cruel y bárbaro exigir que una persona sea mantenida viva contra su voluntad y que se le niega la suplicada liberación cuando su vida ha perdido toda dignidad, belleza, significado y perspectiva de futuro» (The Humanist, julio de 1974).

El quinto lo avala el conocido periodista Indro Montanelli:

«Considero que entre los derechos del hombre también, es más, sobre todo, ha de enumerarse el de poner fin a su vida cuando ésta se haya convertido para él en un calvario de sufrimiento sin esperanza y, dejándolo a merced de otros, le haya privado también de la posibilidad de defender el propio pudor y dignidad» (Corriere della Sera, 23-02-2000). 


\section{El sexto corresponde a Emanuele Severino:}

«Una sociedad que disponde de medios para que una mujer impida el nacimiento de otro ser debería, con mucha más razón, ofrecer los medios que permitan morir a quien, deseando la muerte, no puede autoproporcionársela» (Corriere della Sera, 20-09-1984).

Probablemente, como también se ha puesto suficientemente de relieve por quienes se dedican al estudio de esta problemática, quienes son seguidores de la teoría de la sacralidad de la vida como único fundamento válido y último de la bioética parten de la necesaria correlación descendente, en la que siempre la anterior determina a la siguiente, entre metafísica, antropología y ética ${ }^{70}$. Correlación establecida no en un sentido meramente estáticoontológico que exigiría la formulación conceptual-racional previa del hombre metafísico para desde esa percepción poder alcanzar al hombre ético, sino en una dimensión de prevalencia dinámico-hermenéutica en cuanto que la ética sólo se puede justificar debidamente y fundar racional-comprensivamente por medio de un discurso o elaboración totalizante, complexiva, sobre la persona humana capaz, en consecuencia, de explicar no sólo qué es el hombre, sino cuál es su lugar y función en el mundo y cuál es la causa, motivo y finalidad por la que está en este mundo ${ }^{71}$.

Es claro, pues, sobre todo si partimos del entronque metafísico de los principios o categorías filosóficas de base en que se inspiran, que, probable-

70 «Ogni etica è la conseguenza di una determinata concezione dell'uomo, ed ogni concezione dell'uomo è conseguenza di una determinata concezione della realtà; dell'essere nella sua totalità» (S. VANNI Rovighi, Elementi di filosofia, vol. 3, Brescia 1976, 216). Planteamiento claramente supuesto en la encíclica Fides et ratio de Juan Pablo II cuando defiende que «es necesaria una filosofía de fundamento auténticamente metafísico, capaz de trascender los datos empíricos para alcanzar, en su búsqueda de la verdad, lo absoluto, lo último, lo fundante. Se trata de una exigencia implícita tanto en el conocimiento de carácter sapiencial como en el de carácter analítico; en particular, es una exigencia propia del conocimiento del bien moral, cuyo fundamento último es el Bien sumo, Dios mismo. No quiero hablar aquí de la metafísica como si fuera una escuela específica o una corriente histórica particular. Sólo deseo afirmar que la realidad y la verdad trascienden lo fáctico y lo empírico, y reivindicar la capacidad que el hombre tiene de conocer esta dimensión trascendente y metafísica de manera verdadera y cierta, aunque imperfecta y analógica. En este sentido, la metafísica no se ha de considerar como alternativa a la antropología, ya que la metafísica permite precisamente dar un fundamento al concepto de dignidad de la persona por su condición espiritual. La persona, en particular, es el ámbito privilegiado para el encuentro con el ser y, por tanto, con la reflexión metafísica» (Fides et ratio, n. 83).

${ }^{71}$ «L'obiezione è questa: ma allora bisogna conoscere l'esistenza di Dio come fine ultimo per operare moralmente? Rispondo: non è necessario conoscere l'esistenza di Dio per operare moralmente, ma per giustificare filosoficamente (ossia razionalmente) la moralità. Il che vuol dire: non è detto che chi nega l'esistenza di Dio operi male; ma è certo che tutte le teorie che giusitificano il dovere di operare bene senza ricorrere a Dio finalizzatore sono errate, o almeno incomplete» (S. VANNI RovighI, Elementi..., cit., p. 208) 
mente desde sus orígenes, ha existido y todavía hoy persiste una ruptura estructural, desde su mismo planteamiento teórico, entre la llamada bioética fuerte, de matriz católica, y la denominada bioética debil, de procedencia laica; es decir, entre una bioética metafísica, o estructuralmente abierta a la metafísica, y una bioética no-metafísica, o antimetafísica, que rechaza de plano cualquier referencia a la mera posibilidad de una construcción ontológica de la ética y toda alusión a la existencia de una verdad-metro-norma objetiva capaz de garantizar una regla cierta, sagrada e inviolable orientadora del juicio bioético.

\section{2) ¿Hacia una superación de las diferencias?}

Como era de esperar, ante tan extrema perspectiva no podían faltar las posturas conciliatorias contrarias a la idea de la existencia de una bioética de la cualidad/calidad de la vida radical y esquemáticamente «contrapuesta a una ética de la sacralidad de la vida, sin que se reconozca ciudadanía científica alguna a la infinidad de posturas y opciones intermedias entre estos dos paradigmas», haciendo, además, hincapie en la existencia, dentro del panorama cultural actual, de actitudes menos drásticas y conflictivas:

«La referida contraposición no corresponde a la realidad de las cosas, en cuanto que en ambos frentes el discurso con frecuencia está mucho más articulado y es más sutil — los mismos principios de sacralidad y de cualidad de la vida no definen necesariamente comportamientos radicalmente alternativos, sino que resultan en muchos casos integrables-y las posiciones resultan, en consecuencia, mucho más conciliadoras y dispuestas al compromiso» ${ }^{72}$.

Concordismo ético inmediatamente rechazado, sobre todo desde el lado de quienes mantienen posturas dentro de los principios éticos laicos:

«Se tiene... la sensación de que los dos frentes que se disputan el campo [de la bioética] hubiesen, por decirlo de algún modo, cristalizado sus posiciones, alcanzando un punto de incomunicabilidad substancial, empeñados [cerrados, comprometidos] además... en la discusión sobre el caso concreto y en la defensa a ultranza de las propias posiciones» ${ }^{73}$.

Sin embargo, como ha reconocido el propio Scarpelli, todavía queda la posibilidad de fructuosos encuentros en torno al caso concreto. Según el conocido estudioso, en torno a los casos concretos, sobre todo en aquellos en que se camina en el límite, «las distancias entre una ética religiosa y una ética laica aparecerán más cortas que en las proclamas de principio y, probable-

${ }^{72}$ G. PianA, «I limiti della prospettiva analitica in bioetica», Bioetica, n. 4, 2002, 805.

73 A. Rentería Díaz, «Il principio di autonomia in Uberto Scarpelli», Bioetica, n. 4, 2003, 706. La cursiva es nuestra. 
mente, sobre muchos problemas se podrán hallar senderos comunes» ${ }^{74}$. Pues, en definitiva, todavía siguen lozanas e irresolutas dos preguntas fundamentales en la práctica de la medicina y en los juicios y linderos del moralista más allá de su adscripción ideológica:

- ¿Pueden la investigación médica y la tecnología de que disponemos ser puestas al servicio de quien ha decidido terminar con su propia vida o de quien opta, en principio, por acabar con la vida de alguien para, teóricamente, salvar a otro?

- ¿Qué limites hemos de asumir como individuos, miembros de una sociedad pluralista, a la hora de utilizar todos los medios e instrumentos que la ciencia pone a nuestra disposición y, en este mismo sentido, cuáles han de ser, por el contrario, los puntos de referencia para un creyente a la hora de valorar y enjuiciar problemas de tal complejidad?

No es facil conciliar íntegramente ambas visiones, la laica y la creyente, en la posible respuesta a preguntas de este género, pero ello ni significa ni implica que sea imposible la convergencia en un denominador común. Es evidente que quien vive desde la fe y cree en la vida eterna ha de tener una visión distinta y una actitud diferente ante esta clase de situaciones límite. Pero también es cierto que el respeto por la primacía de la vida y por la dignidad de la persona no es patrimonio exclusivo de los creyentes: el valor incomparable e in-apreciable de la persona humana es, sin duda alguna, patrimonio común de todos los que formamos parte de la sociedad o, al menos, debiera serlo más allá de cualquier fe o creencia. Ésta, y ninguna otra, ha de ser la referencia fundamental a la hora de estudiar y aplicar principios y normas que protejan verdaderamente la vida humana ante cualquier intento de eliminación, mercantilización o reducción a mero bien de consumo.

\section{3) Horizontes de entendimiento}

A pesar de las discrepancias y de las contradicciones apuntadas a lo largo de esta exposición y aun contando con que unas y otras puedan aparecer, con frecuencia, como opuestas hasta la imposibilidad de conciliación alguna, ello no significa de ningún modo que sea imposible el diálogo e incluso la sintonía, en muchos casos, entre los discrepantes, puesto que todos ellos recurren a valores fundamentales en toda solución/opinión sobre los casos o supuestos concretos:

«Las características, que nosotros consideramos revestidas de importancia moral en cada caso, son recibidas a través de valores que previa-

${ }^{74}$ U. SCARPELLI, Bioetica laica..., cit., pp. 27-28. 
mente ya habíamos aceptado en cuanto moralmente relevantes. Siempre tendremos necesidad de ciertas premisas de valor para llegar a conclusiones morales si queremos dar respuesta al cúmulo de circunstancias y problemas a que debemos enfrentarnos» ${ }^{75}$.

Siempre se debe tener presente en el filo de la reflexión, como enseñan los grandes maestros de la bioética laica y católica, que no pueden existir juicios de valor si no responden a determinados principios que, a su vez, estan determinados por entornos de referencia antropológicos y morales. Entornos que, en todos los casos y se opte por la opción de principio que se opte, condicionan las soluciones que se aporten a los casos concretos y que, a su vez, condicionan y fundamentan las diferencias entre los distintos modelos bioéticos:

«Las distintas valoraciones morales sobre las cuestiones específicas derivan del modelo ético de referencia, que siempre y necesariamente se halla presente en la reflexión moral, desde el momento en que la neutralidad en este campo no existe» ${ }^{76}$.

Aun cuando, dados los principios y las opciones de fondo de que se parte, pueda parecer imposible el encuentro entre la bioética personalista o católica o religiosa y la bioética laica, dado que una ética fundada en una antropología que defiende como principio supremo la sacralidad de la vida difícilmente se allanará a soluciones o componendas de cesiones a la debilidad, esto no tiene por qué significar la dejación y pasividad en la búsqueda, siempre en los límites de lo posible, de soluciones convergentes, en orden a suavizar las contradicciones más irreconciliables y las diatribas más lacerantes. Por ello, se sigue insistiendo por parte de quienes sienten profunda preocupación por la persona y sus derechos en que «desde el punto de vista práctico debe de ser máximo [y sin prejuicios castrantes] el esfuerzo en esta dirección. Pero tal búsqueda ha de ser hecha teniendo en cuenta las notables divergencias existentes en el plano teórico. El convencimiento de esta circunstancia aumenta (y no disminuye) la posibilidad de un diálogo sincero y franco entre las partes» ${ }^{77}$.

A pesar de que estructuralmente son distintas e irreconciliables en algunos puntos o aspectos importantes, la verdad es que bioética laica y bioética católica o religiosa están llamadas a entenderse, pues si necesariamente han de coexistir no les queda otra solución que dialogar y, en cierto sentido, inter-relacionarse si realmente se trata de llenar de auténtica humanidad las

75 T. L. Beauchamp, Principialismo, en G. Russo (ed.), Enciclopedia di bioetica..., cit., p. 1399.

${ }^{76}$ M. CASCONE, Diakonia della vita. Manuale di bioetica (Roma 2004), 43.

${ }^{77}$ M. MORI, Per un chiarimento delle diverse prospettive etiche sottese alla bioetica (Milán 1990), 66. 
relaciones interpersonales ${ }^{78}$. Por otra parte, el ambiente multicultural y multiétnico de la mayor parte de las sociedades actuales hace más urgente la necesidad de un verdadero diálogo que no sea la mera y artificial yuxtaposición de monólogos individualistas y estériles, sino la búsqueda comprometida y apologéticamente desapasionada de entendimientos mínimos que posibiliten una convivencia plural en que las discrepancias y desavenencias no sean fruto de odios ideológicos, filosóficos o confesionales, sino consecuencia de la honestidad y sinceridad en la defensa y explicación de las propias convicciones.

\section{El ordenamiento jurídico desde la ética a la sociedad}

Es evidente que la bioética, tanto en lo que se refiere a los problemas que se plantea como a las respuestas que ofrece, se mueve entre dos coordenadas ineludibles: una personal, otra social. La bioética, en cualquiera de sus versiones u orígenes, tiende primaria y principalmente a facilitar medios y criterios de comportamiento y decisión para que las personas abocadas a situaciones límite en las que se pone en riesgo el derecho a la vida y la vida misma puedan decidir y actuar conforme a justicia, moralidad y libertad en el respeto de todos y cada uno de los derechos que se ponen en juego en estos supuestos. Ahora bien, no se debe perder de vista que, cuando se plantea cualquiera de las cuestiones relacionadas con la bioética, comenzamos a movernos en unos ámbitos en que las decisiones personales nunca son privadas/individualistas, sino que, en razón de los sujetos y derechos que se ven implicados y afectados, la proyección social y pública de estas decisiones es ineludible y en modo alguno se puede oscurecer o disminuir esta necesaria dimensión societaria, so pena de afectar a los derechos de la propia persona $\mathrm{y}$, en consecuencia, de rebajar y someter al ser humano a intereses que le son inferiores tanto jurídica como socialmente.

La dimensión e incidencia sociales de los problemas relacionados con la bioética provocan la necesidad de que el ordenamiento jurídico deba interesarse, siempre y exclusivamente desde una perspectiva socio-jurídica, por el

\footnotetext{
${ }^{78}$ Como se ha señalado acertadamente, a pesar de las concesiones que hace a algunos tópicos históricos, por un autor de mentalidad católica «...ci sono società meglio equipaggiate per vivere nel pluralismo ideologico ed etico; altre meno. Senza autolesionismo, possiamo affermare che il nostro mondo latino appartiene piuttosto a queste ultime. Siamo eredi delle crociate e delle guerre di religione, di reazione laiciste a tenaci concezioni teocratiche; ci è più familiare la prevaricazione nei confronti di chi dissente che il rispetto e il dialogo» (S. Spinsanti, Etica biomedica, Cinisello Balsamo 1987, 19). Puede verse también A. SANTosuosso, Una chance per la bioetica e per il diritto, en E. D' Orazio y M. Mori (ed.), «Quale base comune per la riflessione bioetica in Italia? Dibattito sul Manifesto di bioetica laica», Notizie di Politeia 12/41-42, 1996, 56-61.
} 
establecimiento y desarrollo de instituciones jurídicas y estructuras legales que posibiliten, faciliten y garanticen la información y libertad personales ante cualquier decisión del género, tanto por lo que se refiera a la propia persona como a terceros. Por otra parte, difícilmente se podrán articular medidas adecuadas a estas novedosas situaciones si no se abandonan los viejos y, por tantos motivos, caducos esquemas jurídico-políticos del tipo de Estado que surge de la modernidad. La finalidad de la norma ha de tener en su horizonte a la persona y no directa y prevalentemente a cualidades o propiedades de ésta por muy importantes y fundamentales que puedan parecer ${ }^{79}$.

\section{1) La conciencia personal, sujeto y fuente de derecho}

La persona, pues, y su conciencia, por cuanto afecta y se relaciona con los problemas propios y característicos de la bioética, no deben seguir siendo consideradas por el ordenamiento como meros límites negativos de la norma, a través de un conjunto más o menos amplio y mejor o peor articulado de las objeciones de conciencia. Por el contrario, en estos supuestos, la conciencia ha de asumirse como fuente de derecho: la norma, en consecuencia, ha de plasmar la opción de la conciencia y no meramente permitir que, en determinadas circunstancias, la conciencia pueda situarse al margen de la norma.

También ha de tenerse en cuenta, como ya se ha señalado, la fuerte implicación del objeto de la bioética con las opciones y creencias religiosas, así como con usos y prácticas consuetudinarias y culturales. Además, no puede perderse de vista que las sociedades occidentales tienden a ser cada vez más multiétnicas, multirreligiosas y, a pesar de la discutida imprecisión del neologismo, multiculturales. Situación que, a todas luces, complica la

79 «...únicamente pretendemos plantear con la mayor claridad posible la necesidad y la urgencia social de un redimensionamiento personalista, es decir enraizado en la persona, de la relación que necesariamente ha de tener toda norma o institución jurídica con el hombre. $\mathrm{O}$ lo que es lo mismo: estimamos que el centro de cualquier reflexión o concreción normativa de las implicaciones jurídicas de la relacional existencia humana ha de ser siempre la dignidad del hombre. Dignidad que fundamentalmente es la consecuencia social y jurídica, a la vez, necesaria del componente transhistórico, espiritual o trascendente de toda persona y de la radical libertad substancialmente inherente a aquella realidad estructural personal y, a la vez, único medio operativo práctico capaz de realizar, en las coordenadas históricas en que el hombre vive, la verdad [y autenticidad] de su ser humano. Libertad que progresivamente se expresa, y a la vez se plenifica, en la relación existencial que en su desarrollo vital conforman la interioridad personal y su necesaria referencia a la historicidad de toda existencia» (A. CALvo EsPIGA, «Acercamiento a la incidencia...», cit., pp. 319-320). Sobre esta centralidad y exclusividad de la persona como fundamento y razón del ordenamiento jurídico, también puede verse IDEM, Pautas para el análisis de un anacronismo jurídico: ¿ «Derechos humanos» en la Iglesia?, en Actas del Congreso de Teología de las Facultades de Teología de Vitoria y Deusto (Bilbao - Vitoria 1990), 371-373. 
posibilidad de dar respuestas jurídicas desde unos parámetros predominantemente racionalistas que asuman como razón estructurante de la sociedad una uniformidad institucional jerárquicamente ordenada al estilo kelseniano ${ }^{80}$. Se trata, sobre todo, de abandonar actitudes agresivas o defensivas, tantas veces enrocadas en falsas seguridades consecuencia de la absolutización de verdades parciales, para elaborar razonamientos y fijar los márgenes de una senda ética que, respetando radicalmente la libertad de las personas, pueda, en principio, ser aceptada por todos. La urgencia de los problemas y la perplejidad de las situaciones a que la ciencia nos aboca hacen cada día más acuciante el diálogo por la vida y menos comprensible el interés por alzar murallas de incomprensión o hundirse en trincheras ideológicas.

A pesar de su dificultad, más complicada en realidad de lo que a primera vista pudiera parecer, si se quiere dar respuestas válidas y socialmente eficaces en el ámbito de la bioética, no queda más remedio que abandonar los esquemas de la formalidad legal dominante en los ordenamientos democráticos contemporáneos y sustituirlos por la búsqueda de la justicia material, en el respeto y aceptación, como fuente normativa, de la conciencia personal. Como ya sugerimos hace años, probablemente nos hallemos ante la urgencia de retomar principios y metodología de los denominados ordenamientos de conciencia ${ }^{81}$.

80 «Nada mejor que el éxito académico, dogmático y forense obtenido en la organización y jerarquización de las fuentes del derecho por la estructuración piramidal kelseniana para consagrar, bajo apariencia de libertad, la absoluta relativización y marginación de la persona frente a la estructura y, tras la garantía democrática de seguridad jurídica, de la libertad creativa frente a la repetitividad formal, de la espontaneidad social frente a la rigidez de la norma cuya referencia fundamental y justificativa es otra norma, no la persona» (A. CALVO EsPiga, Conciencia..., cit., p. 39).

81 «Así pues, el reconocimiento de las libertades más íntimas de la persona exige del Estado de derecho la progresiva integración de la norma jurídica en la esfera de la actividad social directamente relacionada con y derivada de la conciencia, en su más amplio sentido, del individuo. El ordenamiento estatal se encuentra abocado a regular determinados aspectos de la actividad social de la persona que derivan o se relacionan, de modo especial, con dimensiones extra o metajurídicas del ser humano. Ante esta exigencia, ¿qué capacidad de respuesta pueden tener sistemas jurídicos que no asumen la conciencia de la persona entre sus principios integradores o informadores? Reconocer relevancia a la conciencia personal y a sus implicaciones sociales, ¿no entraría en contradicción con el garantismo formalista y con la seguridad legal-material, propios de los sistemas jurídicos estatales? El Derecho Canónico, en cuanto ordenamiento confesional, puede constituir respuesta ejemplar o modélica a los interrogantes propuestos, ya que, debido a la naturaleza de las relaciones que regula, ha armonizado de tal modo norma jurídica e imperativo de conciencia que posibilita su progresiva integración y, poco a poco, evita o supera los riesgos de conflicto. Por tratarse de un ordenamiento confesional, la norma canónica tiende fundamentalmente a posibilitar la adecuación entre norma jurídica y conciencia, inclinándose siempre por la prevalencia de la conciencia sobre la norma, en caso de conflicto límite en la relación» (A. CALVO EsPIGA, «De nuevo sobre la naturaleza y lugar del Derecho Canónico: derecho confesional 'versus' ordenamiento estatal», Scriptorium Victoriense 44, 1997, 23-24). Para una visión 
La tarea no es fácil y es muy pesado el lastre social y jurídico que se arrastra en las modernas democracias en que formalismo y Estado de derecho han corrido parejos durante décadas y generaciones. Pero la dificultad no debe ser, en modo alguno, equivalente a inacción; al contrario, lo que hoy se exige del jurista es un esfuerzo mayor y una imaginación más despierta al servicio de la persona y de su conciencia tal como existen y se verifican en su situación ideológica, cultural, social y religiosa.

\section{2) Viejos esquemas ante nuevos problemas}

En aquellas sociedades en que las noticias se difundían al ritmo de las caballerías y donde las personas sólo salían de su aldea de origen o a causa de la pobreza, o porque contraían matrimonio o, temporalmente, por razones religiosas, caso de peregrinaciones o determinadas romerías, el principio formal de que la ley es igual para todos supuso una gran conquista donde la única gran diferencia entre las personas radicaba básicamente en el disfrute de importantes privilegios por quienes se acomodaban en las clases altas y en la privación de los derechos más elementales a la gran mayoría de personas que no pasaban de ser súbditos ${ }^{82}$. Sin embargo, la mayor parte de los grandes

ajustada y sintética de las líneas maestras que integran el conjunto sistemáticas de los grandes ordenamientos confesionales de matriz monoteista, puede verse S. FERRARI, El Espíritu de los derechos religiosos. Judaísmo, cristianismo e islam (Barcelona 2004), sobre todo las páginas 91-300.

82 «Au XVI $\mathrm{XI}^{\mathrm{e}}$ siècle, on s'achemine vers le domaine de la propriété privée. Il ne sera vraiment consacré qu' à l' époque révolutionnaire... Ceux qui, aux États généraux, prétendaient représenter le peuple, représentaient en fait la classe bourgeoise. Celle qui vend et qui achète. Dorénavant, vendre et acheter va vous donner le droit d' exister et d' être quelqu' un. C' est ce qui donne une valeur à la personne plus que d' être 'enfant de Dieu'. Au Moyen Âge, le fair d' être des créatures créait une égalité et une unité entre les personnes. Après, on est soit un propriétaire de biens, soit un misérable. Au Moyen Âge, le pauvre représente le Christ. L' expression 'pauvre mais honnête' employée aux XVIII ${ }^{\mathrm{e}}$ et XIX ${ }^{\mathrm{e}}$ siècles est significative: il y a présomption de malhonnêteté pour le pauvre... Au Moyen Âge, on lui faisait une place, même s' il était assis en bout de table. À partir du XVI ${ }^{\mathrm{e}}$ siècle, on a honte du miséreux et on l' exclut. Le fait de posséder de l' argent a créé des classes sociales et entraîné une fracture... Le spectacle d' une société dans laquelle l' argent n' a pas le premier rôle devrait être instructif pour nous: cela permettrait de rétablir des relations qui ne soient pas exclusivement fondées sur le maniement de l' argent» (R. PERnOUd, Histoire et lumière, París 1998, 23 y 24-25). En este mismo sentido, aunque no realiza un análisis tan profundamente centrado en las actitudes personales, ideológicas y religiosas, puede verse O. BRUNNER, Sozialgeschichte Europas im Mittelalter (Gotinga 1978), 135-149 y 158-167. Y desde perspectivas más radicadas en el análisis y estudio de los hechos puede verse R. DeLaTOUCHE, «La crise du XIV ${ }^{\mathrm{e}}$ siècle en Europe occidentale», Les Études sociales 2-3, 1959, 1-19; J. LE GoFf, La civilisation de l' Occident médiéval (París 1964); IDEM, «Le temps du travail dans la 'crise' du XIV ${ }^{\mathrm{e}}$ siècle: du temps médiéval au temps moderne», Le Moyen Âge 69, 1963, 597-613; S. Mochi ONORY, Fonti canonistiche dell’ idea moderna dello stato (Milán 1951). 
principios que han sustentado las viejas democracias se sienten hoy incapaces de dar respuestas jurídicas razonadas, razonables y aceptables a los problemas e interrogantes planteados por las nuevas sociedades conformadas en el fenómeno migratorio/inmigratorio; en el nacimiento de conglomerados sociales estables formados por personas de diferentes razas, idioma, cultura, religión, educación...

Además, al ya complejo problema de la globalización, que ha cambiado, en algunos casos sustancialmente, nuestras referencias ordinarias hasta el extremo de que cuando cada mañana se abre la ventana uno se topa, por ejemplo, con el desastre ecológico sucedido en las antípodas, en lugar de las flores y macetas de la vecina, se ha de sumar, todavía no está claro si por reacción o por estupidez, el renacimiento de particularismos nacionalistas que desvertebran y desarticulan sociedades ya maduras o en evidente proceso de consolidación. Situaciones que, a todas luces, dificultan e incluso imposibilitan soluciones jurídicas desde presupuestos sociales, ideológicos o políticos radicalmente distintos a aquellos que generaron los sistemas hasta ahora conocidos y todavía vigentes.

La centralidad y el respeto a la persona (a la propia persona y a la de los demás), asumido como criterio último de eticidad y, simultáneamente, como valor primario e incondicional de toda bioética a fin de evitar los inconvenientes de las filosofías morales de origen utilitarista, liberal o neoclásico, pueden constituir un buen y seguro inicio y fundamento para consolidar un método de camino común para las distintas opciones y alternativas que priman en la bioética contemporánea ${ }^{83}$. Así, por ejemplo, entre el neoutilitarismo liberal del derecho a morir, que se concreta, predominantemente, en la aceptación de la eutanasia y del denominado suicidio asistido y la utilización de terapias desproporcionadas con la única finalidad de «prolongar biológico-fisiológicamente la vida» cabe una especie de «tercera vía» en la que iniciar una andadura de acompañamiento por parte de las diversas éticas que, de hecho, subyacen a las distintas opciones bioéticas.

${ }^{83}$ En esta línea se mueve, por ejemplo, Massimo Reichlin, uno de los mayores exponentes en Italia de entre quienes intentan abrir vías de diálogo permanentes y aceptadas entre las distintas corrientes de la bioética: «Il riferimento alla persona umana come fonte di valore morale è comune a diverse teorie etiche contemporanee, anche se viene interpretato in maniera significativamente diversa nei diversi approcci: a volte, il valore della persona viene identificato con la considerazione imparziale delle sue preferenze e dei suoi interessi soggettivi, altre volte con il rispetto del suo diritto all'autodeterminazione, altre ancora con la promozione dei suoi beni fondamentali oggettivamente definiti. Mi sembra che, da un lato, le prospettive utilitariste e liberali non rendano ragione del valore intrinsecamente associato all'essere persona, un valore che è prioritario e indipendente rispetto a interessi e preferenze soggettive; dall'altro, che le prospettive fondate sulla legge naturale identifichino troppo rigidamente il rispetto per la persona con il rispetto per i suoi beni fondamentali, rischiando di ricadere in forme di naturalismo, sia pure attenuate» (M. REICHLIN, L'etica e la buona morte, Turín 2002, 181-182). 


\section{3) Persona, norma, conciencia}

El trasunto jurídico de los problemas a que se enfrenta la bioética contemporánea debe asentarse en otros principios y buscar nuevas fórmulas normativas. La conciencia de la persona, tal y como hemos intentado presentarla en estas páginas, puede ser, si se toma con seriedad y consecuencia su dimensión fundamental de fuente normativa y no sólo de límite u objeto, en el mejor caso, de las normas, la mejor opción para ir conformando espacios normativos que brinden cauces, medios y respuestas prácticas y concretas a los retos con que desde la bioética se siente interrogada la sociedad.

Con mayor frecuencia de lo que sería deseable en sociedades democráticas donde, en principio, se invoca a la persona, en su integridad ontológica y moral junto con los derechos que en ella se fundan y a ella protegen radicalmente, como fundamento social y político del conjunto de su sistema normativo, coexisten, más allá de toda lógica jurídica y social, proclamas y declaraciones sobre la urgencia y defensa de aquélla y de éste con actitudes de políticos y legisladores en que, al margen y por encima de cualquier diálogo o discusión ética o moral, promulgan normas sobre delicadísimas cuestiones directamente relacionadas con la vida y la muerte de seres humanos desde la más sutil ignorancia, incluso cínico desprecio, de la persona, de sus derechos, de sus creencias y de su ideología. Con la ya tan manida coartada de la ciencia, se cosifica, se margina, se instrumentaliza, se sacrifica a la persona en el ara de tópicos tan vacíos histórica y científicamente como humanamente peligrosos: progreso, bienestar, ciencia, avance, mejora, calidad de vida, oscurantismos de tiempos pasados... siguen siendo hoy, en época en que tantos divinizan ciencia y racionalidad, acríticos dogmas que esclavizan mentes y normas. Lo que realmente se consigue, por medio de estas actitudes y decisiones, es reducir a la persona a objeto de experimentación o de trueque, según los casos, a favor de proyectos e intereses que poco o nada tienen que ver con la persona.

La bioética, pues, debiera situarse, para ser radicalmente humana, en el vacío creado dentro de las relaciones interpersonales por la separación epistemológica entre ciencia y con-ciencia, a pesar de que la primera, de forma privilegiada a través de la técnica, sigue influyendo masivamente sobre las conciencias. Por otra parte, al aceptar, sin más, una ciencia ilimitada en cuanto a sus posibilidades de avance y superación, se oscurece progresivamente el sentido y necesidad de la conciencia en un doble sentido: en primer lugar porque, de hecho, se acaba identificando ciencia con técnica y ambas con ética; y, en segundo lugar, porque al no interrogarse, en razón de esa ausencia de límites, por el propio sentido y razón de la ciencia, la conciencia queda inconscientemente anegada e invadida en la acomodaticia técnica.

Entre los supuestos que más arriba hemos referido, el ejemplo de la reproducción asistida, caso típico dentro de los problemas a que, en la actualidad, se enfrenta la bioética, puede ayudar a explicitar y concretar lo dicho. Todo el proceso generativo, desde la concepción al parto y a la asunción del 
hijo, está orientado, marcado y determinado por la técnica. Y, de hecho, consciente o inconscientemente, así es percibido por quienes realizan esta experiencia. La pregunta surge con radicalidad no ya tanto desde el ámbito público de leyes y normas, sino desde la vivencia íntima, personal, única de quien o quienes asumen y se someten a una experiencia de esta clase. $\mathrm{O}$, dicho de otro modo, ¿puede responderse con honestidad, desde desnudos y asépticos principios generales de carácter jurídico o filosófico, al hecho incontestable de que una técnica anónima y puramente material se convierta en referente dialogal necesario de la persona en una de las decisiones más íntimas y comprometidas que puede adoptar un ser humano? ¿No debería la bioética, sobre todo en su dimensión de eqos, preguntarse por el propio sentido y razón de la ciencia, sobre todo en lo que afecta directamente a la persona?

Y si esto se hiciera con autenticidad científica, ¿no nos abocaría necesariamente, desde una perspectiva radicalmente personalista, a la conciencia como razón última y sentido de la relación ciencia-persona?

Nos planteábamos al principio de esta reflexión si no cabría hablar, dada la deriva por la que en tantas ocasiones se desliza la bioética, más de thánatos-ética que de bio-ética y quizás, si seguimos leyendo, pensando y preocupándonos de estos temas, debamos preguntarnos si la bioética tiende, de hecho, tal y como se plantea tantas veces a proteger y garantizar la vida o más bien busca legitimadoras coartadas para la muerte. Ėthos significa morada habitual, lugar en el que uno se siente al reparo y protegido, y bio-ética debiera ser, por tanto, el arte de vivir y la misión de profundizar en la seguridad de una vida protegida... quien tenga cabeza para pensar ;que piense! 